\title{
Design Considerations for Large Mass Ultra-Low Background Experiments
}
E Aguayo
JE Fast
DJ Reid
JL Orrell

July 2011

Pacific Northwest

NATIONAL LABORATORY

Proudly Operated by Battelle Since 1965 


\title{
DISCLAIMER
}

This report was prepared as an account of work sponsored by an agency of the United States Government. Neither the United States Government nor any agency thereof, nor Battelle Memorial Institute, nor any of their employees, makes any warranty, express or implied, or assumes any legal liability or responsibility for the accuracy, completeness, or usefulness of any information, apparatus, product, or process disclosed, or represents that its use would not infringe privately owned rights. Reference herein to any specific commercial product, process, or service by trade name, trademark, manufacturer, or otherwise does not necessarily constitute or imply its endorsement, recommendation, or favoring by the United States Government or any agency thereof, or Battelle Memorial Institute. The views and opinions of authors expressed herein do not necessarily state or reflect those of the United States Government or any agency thereof.

\author{
PACIFIC NORTHWEST NATIONAL LABORATORY \\ operated by \\ BATTELLE \\ for the \\ UNITED STATES DEPARTMENT OF ENERGY \\ under Contract DE-AC05-76RL01830
}

Printed in the United States of America

$$
\begin{aligned}
& \text { Available to DOE and DOE contractors from the } \\
& \text { Office of Scientific and Technical Information, } \\
& \text { P.O. Box 62, Oak Ridge, TN 37831-0062; } \\
& \text { ph: (865) 576-8401 } \\
& \text { fax: (865) 576-5728 } \\
& \text { email: reports@adonis.osti.gov }
\end{aligned}
$$

Available to the public from the National Technical Information Service

5301 Shawnee Rd., Alexandria, VA 22312 ph: (800) 553-NTIS (6847)

email: orders@ntis.gov <http://www.ntis.gov/about/form.aspx>

Online ordering: http://www.ntis.gov 


\title{
Design Considerations for Large Mass Ultra-Low Background Experiments
}

\author{
E Aguayo \\ JE Fast \\ DJ Reid \\ JL Orrell
}

July 2011

Prepared for

the U.S. Department of Energy

under Contract DE-AC05-76RL01830

Pacific Northwest National Laboratory

Richland, Washington 99352 



\section{Summary}

The objective of this document is to present the designers of the next generation of large-mass, ultra-low background experiments with lessons learned and design strategies from previous experimental work. Design issues divided by topic into mechanical, thermal and electrical requirements are addressed. Large mass low-background experiments have been recognized by the scientific community as appropriate tools to aid in the search for physics beyond the Standard Model. The design of these experiments is very costly and a rigorous engineering review is required for their success. The extreme conditions that the components of the experiment must withstand (heavy shielding, vacuum/pressure and temperature gradients), in combination with unprecedented noise levels, necessitate engineering guidance to support quality construction and safe operating conditions. Physical properties and analytical results of typical construction materials are presented. Design considerations for achieving ultra-low-noise data acquisition systems are addressed. Five large-mass, low-background conceptual designs for the onetonne scale germanium experiment (S4) are proposed and analyzed. The result is a series of recommendations for future experiments engineering and for the Majorana simulation task group to evaluate the different design approaches. 



\section{Acronyms and Abbreviations}

$\begin{array}{ll}1 \text { TGe } & \text { One-tonne }{ }^{76} \text { Ge neutrinoless double-beta decay experiment } \\ \text { DAQ } & \text { data acquisition } \\ \text { EFCu } & \text { Electroformed copper } \\ \text { FEA } & \text { finite element analysis } \\ \text { FEE } & \text { front-end electronics } \\ \text { FET } & \text { field-effect transistor } \\ \text { HPGe } & \text { high purity germanium } \\ \text { LAr } & \text { liquid argon } \\ \text { LN } & \text { liquid nitrogen } \\ \text { MJD } & \text { MAJORANA Demonstrator } \\ \text { OFHC } & \text { oxygen free high conductivity copper } \\ \text { PNNL } & \text { Pacific Northwest National Laboratory } \\ \text { RTD } & \text { resistive thermal device }\end{array}$





\section{Contents}

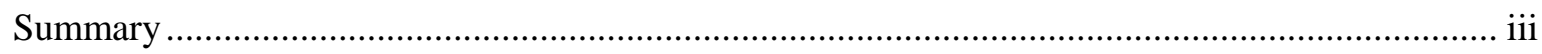

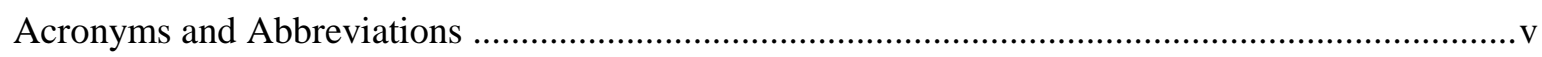

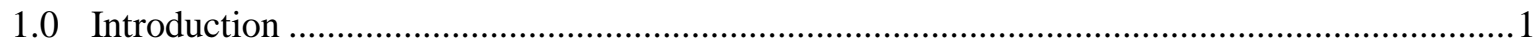

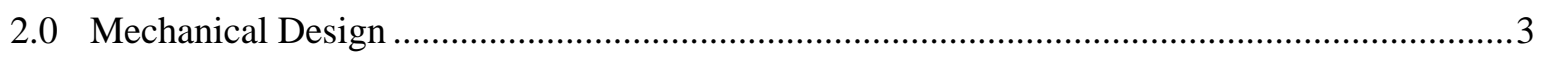

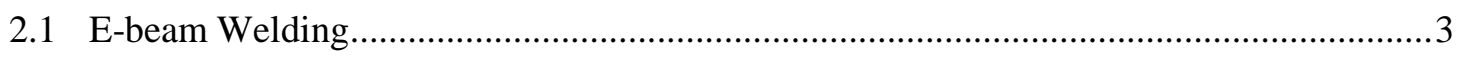

2.2 Copper Weld Strength Test Results ........................................................................

2.3 Stainless Steel Bellows for Mechanical Decoupling ...................................................6

2.4 Vacuum Failure Risk Analysis .............................................................................

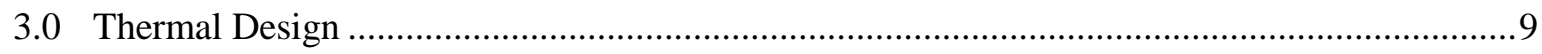

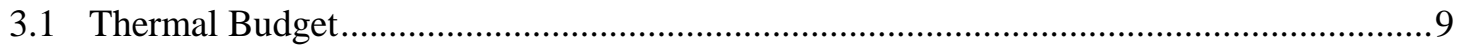

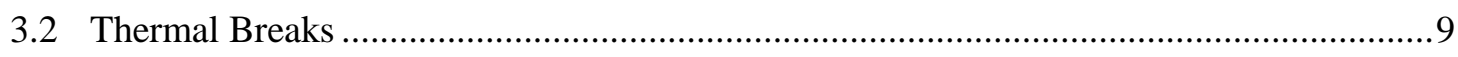

3.3 Copper-to-Copper Bolted-Joint Thermal Resistivity Measurement................................ 10

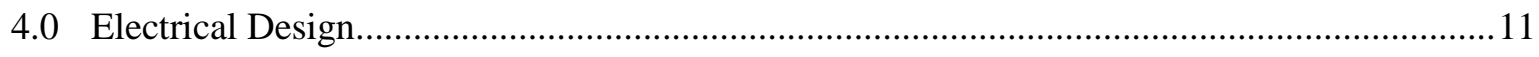

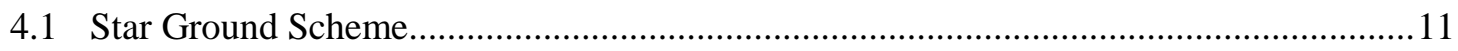

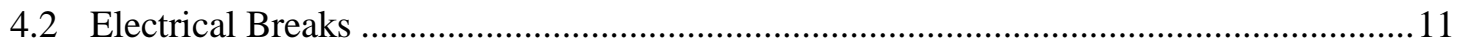

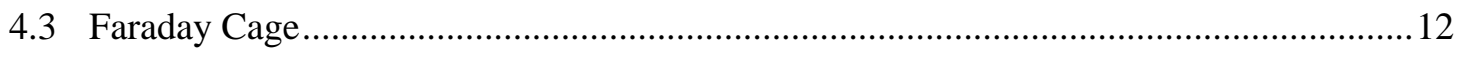

5.0 1TGe Compact High-Z Shield Cryostat (Shield Geometry \#1) Analysis .............................. 15

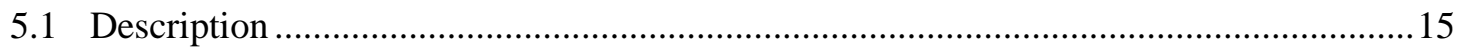

6.0 1TGe Direct Immersion in LAr/Water (Shield Geometry \#2) Analysis................................. 17

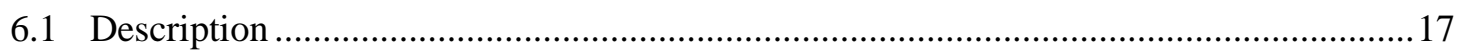

7.0 1TGe Vacuum Cryostat in LAr/Water (Shield Geometry \#3) Analysis ................................. 19

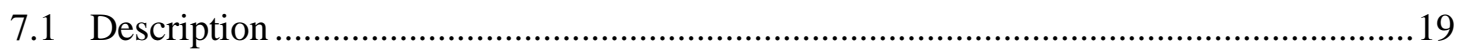

8.0 1TGe Vacuum Cryostat in Liquid Scintillator (Shield Geometry \#4) Analysis ......................21

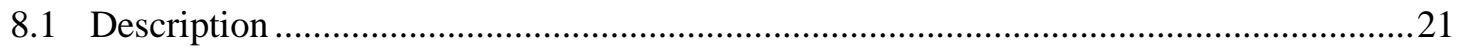

9.0 1TGe Vacuum Cryostat in Water (Shield Geometry \#5) Analysis ......................................23

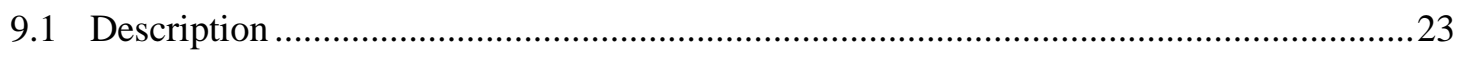

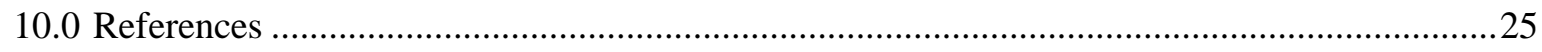

Appendix A Vacuum Failure Heat Leak................................................................................... 1

Appendix B Expected Error in the Proposed Copper-to-Copper Thermal Joint Test.................... B.1 


\section{Figures}

Figure 1. Inner Chamber of PNNL E-beam Welder ..................................................................

Figure 2. PNNL E-beam Welder.......................................................................................

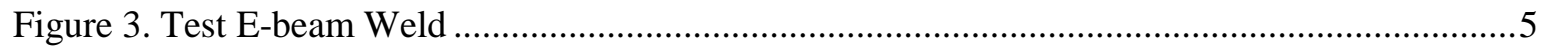

Figure 4. Bellows as Mechanical Decouplers in the MJD Cross Arm...........................................

Figure 5. Conceptual Model of the Copper Thermal Joint Test Fixture ......................................... 10

Figure 6. Conceptual Schematics of a Star Ground Configuration................................................ 11

Figure 7. 1TGe Shield Geometry 1 Model [Steele 2011] .......................................................... 15

Figure 8. 1TGe Shield Geometry 2 Model [Steele 2011] ............................................................ 17

Figure 9. 1TGe Shield Geometry 3 Model [Steele 2011] ............................................................ 19

Figure 10. 1TGe Shield Geometry 4 Model [Steele 2011] ............................................................21

Figure 11. 1TGe Shield Geometry 5 Model [Steele 2011] ........................................................23

\section{Tables}

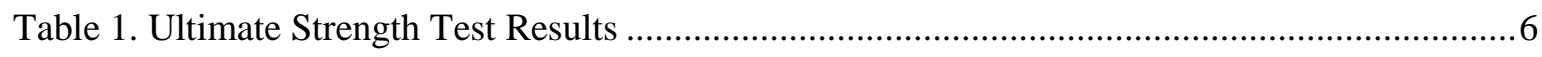

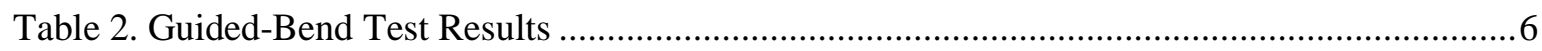

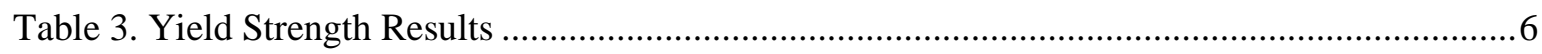

Table 4. Vacuum Failure Risks and Preventative Actions............................................................. 8

Table 5. Heat Loads per Cryostat for Several HPGe Experiments ................................................

Table 6. Relative Risk of Electromagnetically Induced Noise ................................................... 13

Table 7. Identified Risks and Proposed Actions for Shield Geometry 1 ....................................... 16

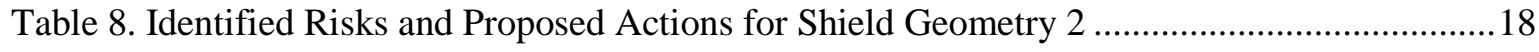

Table 9. Identified Risks and Proposed Actions for Shield Geometry 3 .....................................20

Table 10. Identified Risks and Proposed Actions for Shield Geometry 4 ....................................22

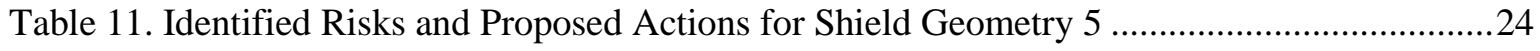




\subsection{Introduction}

Large mass and low backgrounds are two very challenging requirements of a double-beta decay germanium experiment. Meeting both requirements pushes the limits of technology to unprecedented levels of complexity. The challenges faced by a low-background, large-mass experiment design must be thoroughly addressed and the failure risks minimized to secure a successful implementation. The onetonne ${ }^{76} \mathrm{Ge}$ neutrinoless double-beta decay experiment (1TGe or S4) will be a scaled-up version of the MAJORANA DEMONSTRATOR (MJD) [1]. The final detector array is projected to hold up to $500 \mathrm{~kg}$ of germanium detectors. The design is approached from several different topic areas in this document: Mechanical, thermal, and electrical considerations are outlined in sections 2-4. Five conceptual designs are presented in sections 5-9.

The mechanical soundness of such a large-mass experiment must be guaranteed and the limits for mechanical failure precisely stated. One of the most complex issues of the mechanical structure is preventing direct line of sight into the detector chamber and minimizing shield penetration area. A side penetration of the shield is used in the MJD design to minimize shinning paths into the detector active volume. The mass of the MJD detector is supported by welded parts. A clean welding technique is presented in Section 2 of this document. In order to determine the limits of the technique presented, a precise measurement of the mechanical strength of the weld used in the construction of the experiment is mandatory. Electroformed copper is the most common material used in the design of low-background experiments. The welds are the most likely site for a mechanical failure. These welds must be performed without contaminating the weld surfaces. One possible source of contamination in the weld joints is the use of thoriated welding rods; the preferred welding technique is e-beam (electron beam) welding. The results of a pull test performed on e-beam welded copper rods are presented in Section 2. Vacuum failure is one of the most worrisome risks in such an experiment: The causes and consequences of a vacuum failure are varied, and each one must be addressed differently. A rough guide to minimize risks associated with this failure mode is presented at the end of Section 2.

Once the mechanical conceptual design is complete, the thermal properties of the design must be analyzed. The germanium crystals operate best at liquid nitrogen temperatures $(\sim 80 \mathrm{~K})$. The temperature profile along the detector array must be kept to a minimum in the three spatial dimensions of the experiment's cryostat; temperature gradients greater than $10 \mathrm{~K}$ will make the detector inoperable. A balance must be reached between granularity (prefers having the crystals close to each other) and thermal radiation between adjacent crystals (prefers the crystals far from each other). The cooling must be done in a clean manner to minimize condensation of contaminants close to the detector array. A thermal budget must be implemented in order to estimate the required cooling power and delivery of such cooling power. A template thermal budget is outlined in Section 3 of this document. The use of copper as a thermal joint is very favorable in large-mass low-background experiment; the MJD design uses a copper joint to thermally couple the cold plate and thermosyphon evaporator tube. This document describes a proposed experiment to measure the thermal resistivity of bolted copper joints.

The last aspect of the design of the ultra-low background large-mass experiment discussed in this document is the electromagnetic shielding of the detector channels and the routing of the feedback currents to minimize induction of noise in the detector's output during operation. This is most critical for dark-matter search applications of the germanium array. The star grounding scheme is outlined in Section 4 and the required electrical breaks that must be considered in large-mass detectors are addressed. 
Another risk to the noise performance of the experiment is presented by the wiring of the detector. The amount of insulating materials used should be limited by the background budget. Insulation such as parylene is very likely to be a major contributor to the background budget. The amount of parylene in a direct line of view of detector channels must be minimized. The length of the wires is also a risk in terms of performance for the experiment. Longer wires require thicker ground cables to reduce resistivity.

The S4 project is in a feasibility evaluation process. Five geometries have been proposed for the experiment by collaborators with experience in other low-background germanium experiments. The proposed shield geometries 1, 2, 3, 4 and 5 for the 1TGe project are presented and analyzed. Cryostat 1 is a scaled-up version of the MJD cryostat; the experiment detector mass would be divided into eight cryostats, and each cryostat diameter would be increased from $0.33 \mathrm{~m}$ in the MJD to $0.48 \mathrm{~m}$. Cryostat 2 is based on the concept of having all detector mass in a single cryostat in an oxygen-free, high thermal conductivity (OFHC) copper shield lined with electroformed copper, and submerged in liquid argon. Cryostat 3 is based in the MJD cryostat structure with taller cryostats to optimize efficiency and granularity. This design also cools the cryostat by lowering it into a liquid argon shield. Cryostats 4 and 5 present a similar architecture, with changes to the shielding material. 


\subsection{Mechanical Design}

The shield design should avoid, as much as possible, direct line of sight of the detector mass; this requirement makes the support of large masses in shielded environments a challenge. In the MJD, a modular assembly with horizontal access through the shield architecture is used, and welded pipes support the weight of the detector. In this section a clean technique for welding copper pipes is presented, and recommended tolerances are described. The ultimate tensile strength gives the designer an idea of the number of supports required for a given experiment mass. To make sure that the experiment passes safety reviews, the maximum weight per unit area should be three times lower than the ultimate strength.

\subsection{E-beam Welding}

The e-beam welding set-up at PNNL is described in detail in this subsection. The inside chamber of the e-beam welder at PNNL has inside dimensions of $0.9 \mathrm{~m}$ (36") long, $0.9 \mathrm{~m}$ (36") wide, and $1.32 \mathrm{~m}$ (52") tall. The actual usable space for welding parts is significantly smaller than that, because of the fixturing. Typically the part size can be $0.6 \mathrm{~m}$ (24") tall, $0.38 \mathrm{~m}$ (15") long, and $0.56 \mathrm{~m}$ (22") wide. PNNL's e-beam welder is capable of a maximum penetration of 1/8 inch into copper. Figure 1 shows the inside vacuum chamber of the welder with a copper-hoop weld fixture in the center. The vacuum chamber of the welder is unclean, having several deposits from non-controlled materials. The chamber is lined with foil paper to minimize contamination. This lining will be removed and replaced with clean foil paper when the MJD components are to be welded. Figure 2 shows the PNNL e-beam welder. Figure 3 shows a welded copper part; the crystallization follows the electron beam path, the point furthest from the beam being the narrower point in the crystallization pattern (the inner surface of the welded parts and the lower surface in Figure 3). This was a failed weld, since the space created at the inner surface of the weld could potentially outgas into the vacuum space; this problem has been solved by having a tiny space between the alignment lips so this trap-formation effect can be avoided. 


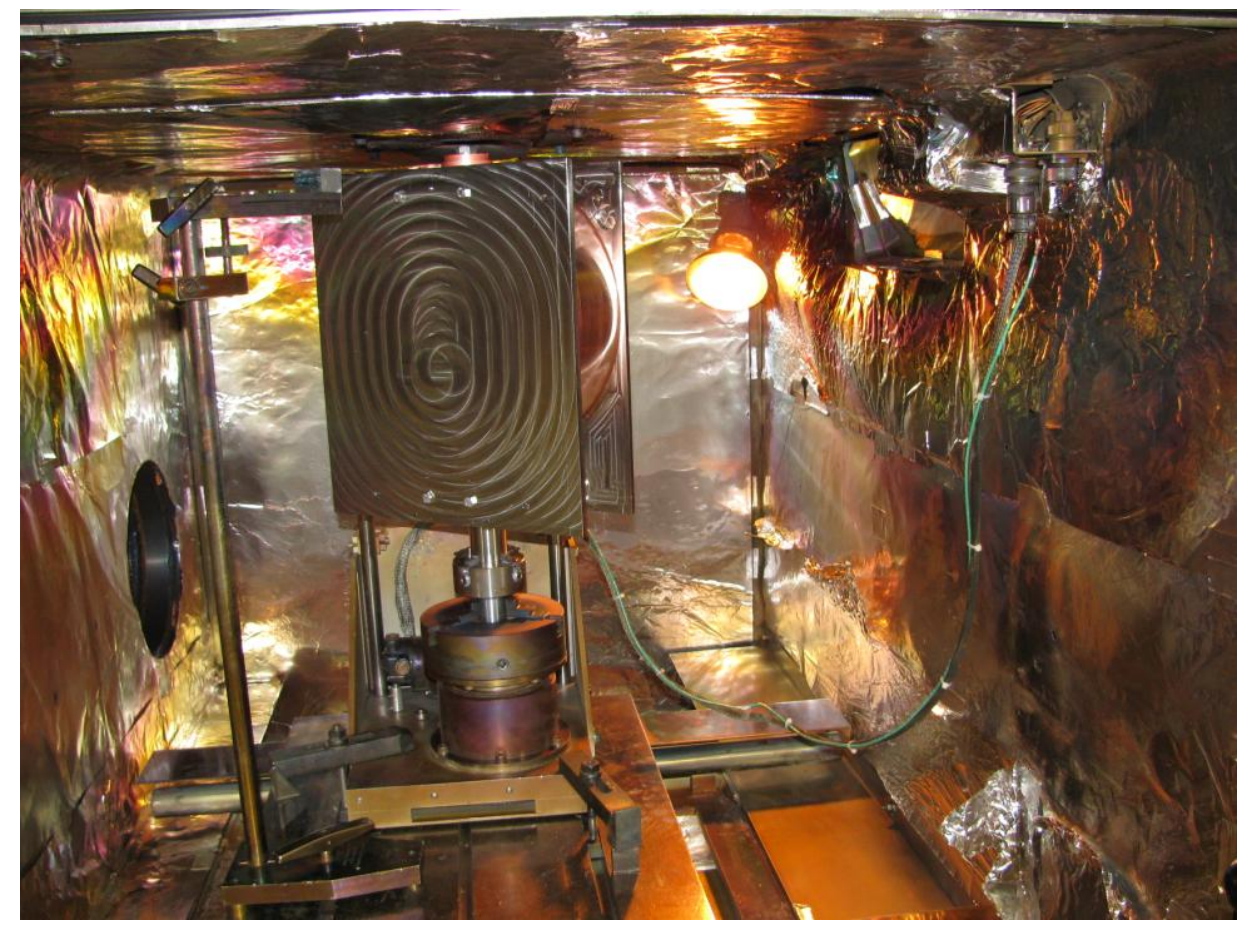

Figure 1. Inner Chamber of PNNL E-beam Welder

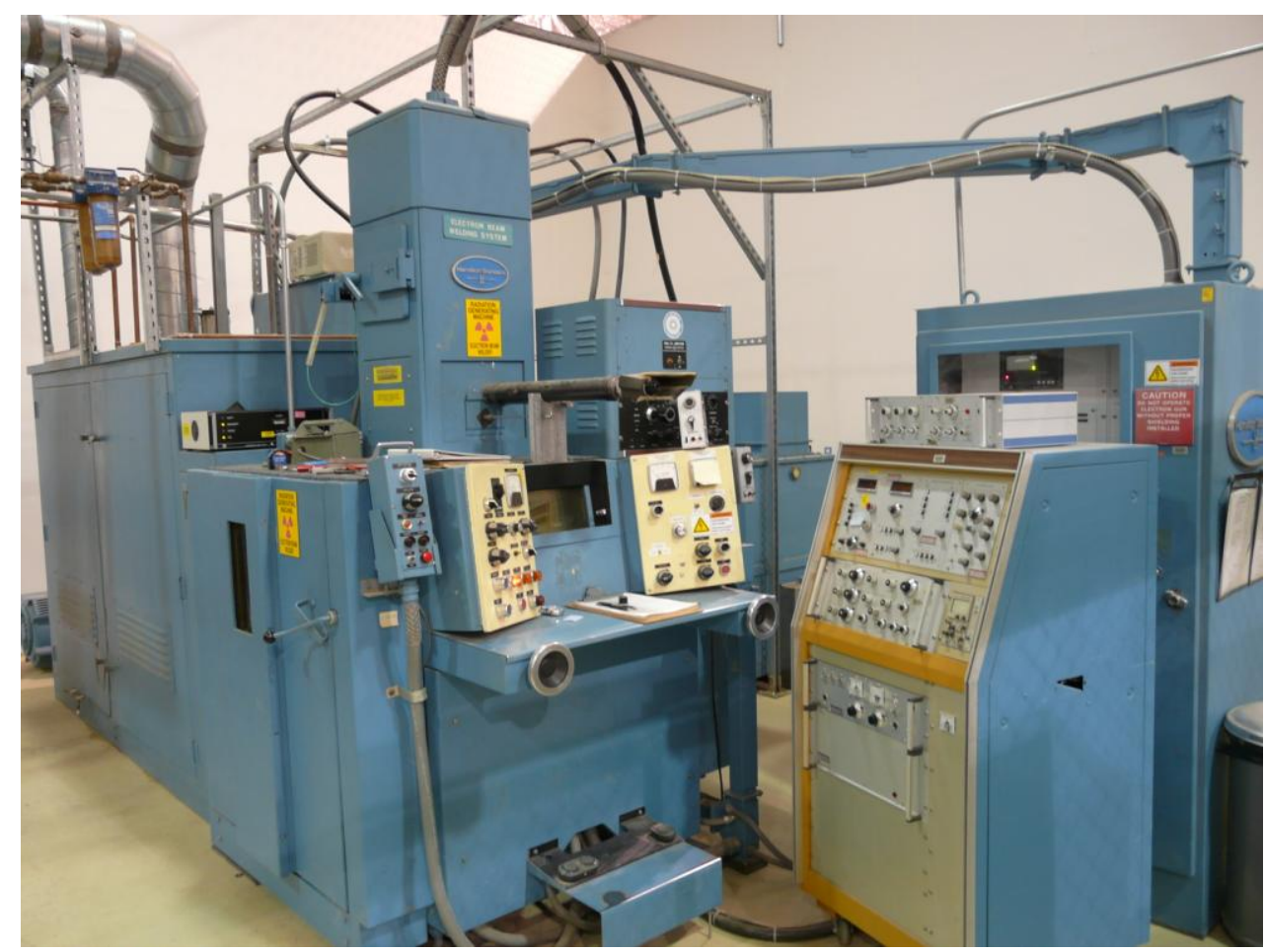

Figure 2. PNNL E-beam Welder 


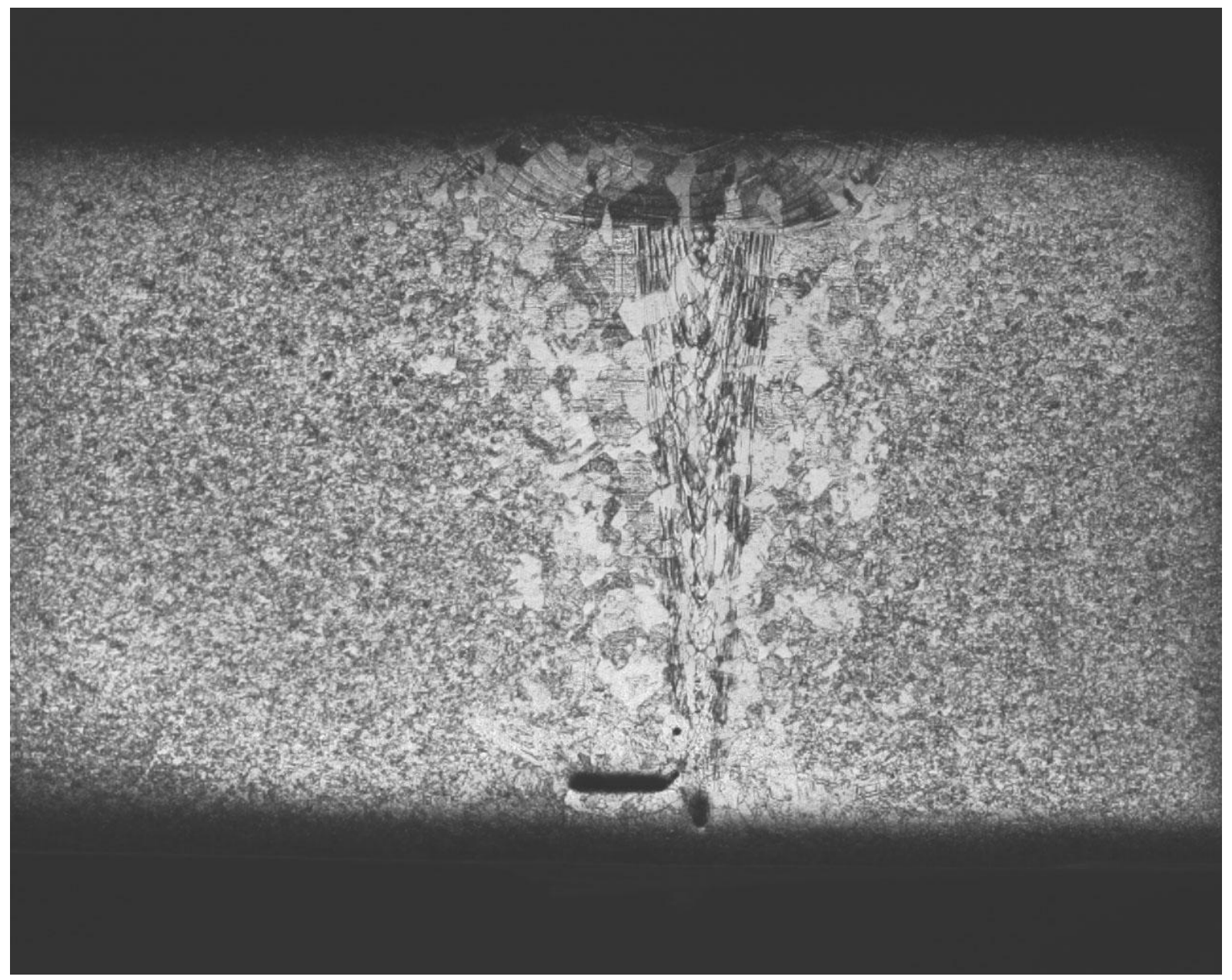

Figure 3. Test E-beam Weld

\subsection{Copper Weld Strength Test Results}

Twelve copper tube samples $0.025-\mathrm{m}$ (1") in diameter with 1/8-inch wall thickness were welded with the setup described in Section 2.1. Some of these samples were tensile tested at room temperature for ultimate and yield strength. Others were subjected to a guided-bend test. A specification for the testing methods can be found in [ASME 2010]. Table 1 presents the results of the ultimate tensile test. The result is that the ultimate tensile strength is very close to the parent material's ultimate strength of 32 ksi minimum [CDA 2011] in this test copper. Results deviated less than $4 \%$ among the different parts. Based on the test results, each welded copper pipe joint is capable of supporting a load of 5,000 lbs in tension. Table 2 presents the results of $180^{\circ}$ guided-bend tests with a bend diameter of one inch. The "incomplete fusion" comment in Table 2 refers to an observed ditch in the pipe after bending; this is an engineered feature to facilitate alignment during the welding process and avoid potential gas entrapment in the interior weld surface. Table 3 presents the yield strength results using the $0.2 \%$ offset method. 
Table 1. Ultimate Strength Test Results

\begin{tabular}{lllll}
\hline Part Number & Area $\left(\mathrm{in}^{2}\right)$ & Load (lbs.) & Ultimate Tensile Strength (ksi) & Fracture Location \\
\hline 2412-WLD1 & 0.4681 & 14575 & 31.1 & At weld \\
2412-WLD2 & 0.4715 & 14050 & 29.8 & At weld \\
2412-WLD3 & 0.4711 & 14425 & 30.6 & At weld \\
2412-WLD4 & 0.4706 & 14525 & 30.9 & At weld \\
\hline
\end{tabular}

Table 2. Guided-Bend Test Results

\begin{tabular}{lll}
\hline Part Number & Bend type & Comments \\
\hline 2412-WLD5 & Root & Incomplete fusion \\
2412-WLD6 & Root & Incomplete fusion \\
2412-WLD7 & Root & Incomplete fusion \\
2412-WLD8 & Root & Incomplete fusion \\
2412-WLD9 & Face & Acceptable \\
2412-WLD10 & Face & Acceptable \\
2412-WLD11 & Face & Acceptable \\
2412-WLD12 & Face & Acceptable \\
\hline
\end{tabular}

Table 3. Yield Strength Results

\begin{tabular}{llll}
\hline Part Number & Yield Strength $(\mathrm{ksi})$ & Fracture location & Sample \\
\hline $5605-$ WLD5A & 7.8 & In weld & Tube \\
$5605-$ WLD6 & 8.4 & In weld & Tube \\
$5605-$ WLD7 & 11.1 & In weld & Flat \\
$5605-$ WLD8 & 9.9 & In weld & Flat \\
\hline
\end{tabular}

\subsection{Stainless Steel Bellows for Mechanical Decoupling}

Microphonic vibrations could deteriorate the resolution of the MJD experiment. Although no controlled experimental data exist to characterize the response of high-purity germanium (HPGe) detectors to micro vibrations, it is very noticeable in the output signal when working with detectors in the lab. Recent dark-matter search results mention microphonics as a possible cause of part of the signals in the observed low-energy range $(<4 \mathrm{keV})$ [Aalseth et al. 2010]. These micro-vibrations are generated in the service body and in the cryogenic system. The service-body vibrations can be partially attenuated using stainless-steel bellows. Cryogen boiling can generate undesirable microphonic noise in the experiment. A detailed study of these effects is being developed by the MJD Collaboration. Figure 4 shows the decoupling mechanical bellows in the crossarm of the MJD. 


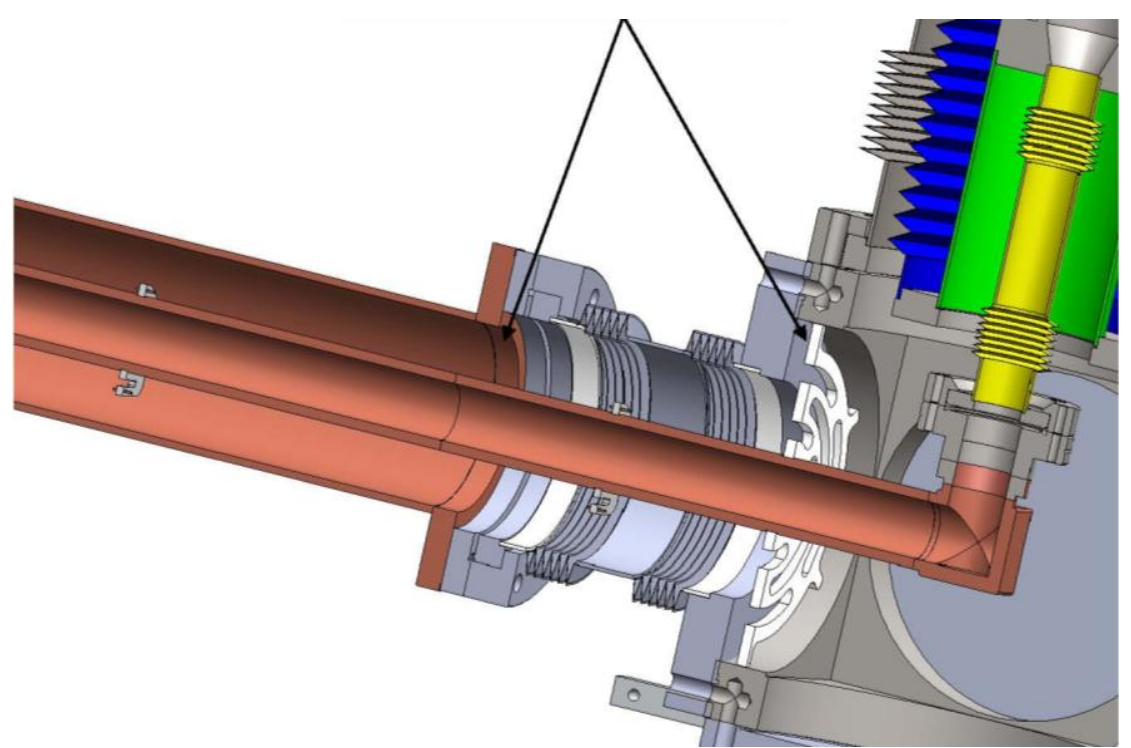

Figure 4. Bellows as Mechanical Decouplers in the MJD Cross Arm

\subsection{Vacuum Failure Risk Analysis}

When designing detectors based on HPGe, the cryostat is traditionally kept under vacuum conditions during operation; this is done in order to prevent heat leaks due to convection, contamination, and electrical failure of the detector circuitry (caused by surface contaminants forming electrical paths between anode and cathode in the crystal and HV discharges). A vacuum failure will simultaneously disrupt the thermal, mechanical and electrical behavior of the experiment.

There are a couple of situations where a vacuum failure could happen; the risk mitigation depends on the nature of the vacuum failure problem. Table 3 lists the major risks associated with a cryogenic system failure and response actions to prevent detector damage. Pressure relief valves prevent pressure buildup in the experiment's vacuum chamber and Dewar chamber. In all cases the electronic system should be completely shut off if a loss of vacuum is detected. In case of a Dewar containment failure, cryogen could reach the vacuum chamber and be heated rapidly by radiation and conduction. The handling of the cryogen in such scenarios must be addressed in order to maintain safe operation. The design must account for all situations to prevent the pressure of the system exceeding projected levels. Sizing of the relief valve must consider the worst-case scenario, in which the cryogen needs to be evacuated without back-pressure build up. The pipe flow must accommodate the volume of cryogen expanding at a rate driven by the heat leaked into the system and heat of vaporization. Appendix A gives the calculation for the heat leaked into the MJD thermosyphon in case of vacuum failure.

Table 4 shows the failure scenarios considered in the design of the MJD. In case of puncture of the cryostat the insulating cryostat vacuum will be lost to air. The heat entering the thermosyphon via convection will increase the pressure in the thermosyphon and lower its operating temperature until reaching a point where the working nitrogen will expand to room temperature conditions. In case of a mechanical failure of the Dewar the nitrogen bath will be lost due to nitrogen boil-off. The loss of the Dewar insulation vacuum to nitrogen is also considered a Dewar failure. This has been identified as the worst accident scenario from a heat load point of view because convection will occur in the whole external surface of the Dewar (the biggest volume in the cryogenic system). In this case the 
thermosyphon will not be able to evacuate interchange heat through the condenser and this will result in the expansion of this gas. In the case of a pump failure, power failure, temperature increase in the environment, or cryogen dry-out the consequences are identical as in the first case considered. The cryogen system must have a large enough ballast tank connected to the thermosyphon to allow gas expansion in these failure scenarios. In case of a short in the power lines, the cryogen system would be unaffected, unless the failure affects a pump valve. In this case the failure will be masked, and it is important to make sure that the liquid nitrogen supply line is not shut off, or it will cause a cryogen dryoff situation.

Table 4. Vacuum Failure Risks and Preventative Actions

\begin{tabular}{ll}
\hline Risk & Response \\
\hline Puncture of the cryostat & $\begin{array}{l}\text { Electronics shut off using real-time pressure readings, pressure } \\
\text { relief valve in Dewar and cryostat } \\
\text { Pechanical failure of Dewar }\end{array}$ \\
$\begin{array}{l}\text { Pressure relief valve, proper room ventilation to prevent } \\
\text { suffocation and emergency electronics shut off. } \\
\text { Electronics shut off using pressure readings; large ballast tank to } \\
\text { allow proper gas expansion in thermosyphon. }\end{array}$ \\
$\begin{array}{l}\text { Large ballast tank designed to allow cryogen expansion } \\
\text { Power failure }\end{array}$ & $\begin{array}{l}\text { Electronics shut off using real-time temperature readings and } \\
\text { large ballast tank to allow proper gas expansion in thermosyphon. }\end{array}$ \\
$\begin{array}{l}\text { Supply-line shorts with vacuum } \\
\text { jacket }\end{array}$ & $\begin{array}{l}\text { Electronics shut off using real-time current consumption readings } \\
\text { Temperature rise in the lab (due to }\end{array}$ \\
fire in the mine) & $\begin{array}{l}\text { Electronics shut off using real-time temperature readings; } \\
\text { pressure relief valves in ballast tank; release of excess pressure in } \\
\text { Dewar. }\end{array}$ \\
\hline
\end{tabular}




\subsection{Thermal Design}

\subsection{Thermal Budget}

In any cryogenic cooling application, the required cooling capacity or heat load determines the amount of cryogen needed. Typically, the smaller the cryogenic heat load, the smaller the input power requirement and physical size of the cooling system. Minimizing the cryogenic heat load should be a major goal in the design of large-mass low-background experiments. In designing a cryogenic system, the most prominent component of the power budget should be the radiated heat into the system, which is intrinsic to the shield geometry and cryostat size. Conductive heat loads can be minimized by optimizing materials of construction and inserting thermal breaks. Radiative and convective heat loads can be reduced by maintaining a sufficient vacuum at all times. This would make the thermal budget in its majority directly proportional to the volume of the cryostat in the experiment. As a bonus, by maintaining radiation as the major contributor to the thermal budget, the designer facilitates the stable thermal operation of the system because the radiated and conductive heat components of the heat load are always stable; if the heat load is dominated by other components of the system, the system has greater potential to become unstable. In particular, in a case in which the thermal budget is dominated by the front-end electronics (FEE) component, if the number of operating detectors in the system is changed (due to maintenance or failure) the system operating point could change. Table 5 presents the heat loads for several large-mass low-background experiments; the calculations can be found in Appendix A. The heat load associated with the electronics is proportional to the number of individual detector channels inside the cryostat; a conservative estimate of $100 \mathrm{~mW}$ per channel was used in the data presented in Table 4. The conductive heat is proportional to the weight of the detector mass inside the cryostat; larger detector mass per cryostat requires thicker supports which would result in greater heat leakage via conduction through this thermal path. The calculations for the MJD and S4C1 were taken from a previous PNNL report [Reid et al. 2011].

Table 5. Heat Loads per Cryostat for Several HPGe Experiments

\begin{tabular}{ccccccc}
\hline & MJD & S4C1 & S4C2 & S4C3 & S4C4 & S4C5 \\
\hline Radiative (W) & 2.3 & 3.1 & 0.0 & 0.1 & 6.2 & 6.2 \\
Electronics & 3.5 & 9.5 & 25.0 & 6.3 & 6.3 & 6.3 \\
Generated (W) & & 0.5 & 0.0 & 0.0 & 0.0 & 0.0 \\
Conductive (W) & 0.3 & 0.0 & 0.0 & 0.0 & 0.0 & 0.0 \\
Convective (W) & 0.0 & &
\end{tabular}

\subsection{Thermal Breaks}

In order to maintain thermal stability, the system must balance the heat entering the system via conduction. Points that allow heat conduction should be kept to a minimum. Usually these conductive heat paths are located in the fill ports of the Dewar and in the supports for the detector strings (in MJD and $\mathrm{S} 4 \mathrm{C} 1$, the cold-plate supports). In the MJD there is also a conductive heat path in the transition bellows between the Dewar vacuum space and experiment vacuum space. A high-thermal-resistivity material, such as stainless steel, is used, with an extended length in form of bellows to make the thermal path more resistive. 
The MJD and compact shield geometry \#1 for 1 TGe cryostats are held by several PolyEtherEtherKetone (PEEK) supports. The heat load of this conductive thermal path is presented in the "Conductive" row in Table 5.

\subsection{Copper-to-Copper Bolted-Joint Thermal Resistivity Measurement}

The tip of the horizontal evaporator tube of the thermosyphon and the cold plate will be bolted together. Designated the cold plate interface, this section of the thermosyphon is where a set of bolts will press the cold plate and cold plate interface to make mechanical (and thermal) contact between the cold plate and the thermosyphon. Both the thermosyphon evaporator tube and the cold plate will be manufactured using ultrapure copper, the traditional material used to construct ultra-low-background detectors. The cold-plate interface thermal resistivity is a critical parameter and is needed to predict the operating temperature of each detector crystal in MJD.

The thermal path between the Dewar (heat sink) outside the shield and the detector inside the cryostat (heat source) crosses several interfaces. Two conductive interfaces that are in direct contact with the internal closed system are the condenser section of the Dewar and the cold plate interface.

Experiments for characterizing of the behavior of these thermal interfaces are being designed as part of the MJD development. The proposed experiment will aid in understanding the thermal behavior of the copper-to-copper bolted joint between the cold plate interface and the cold plate. Figure 1 shows a model of the proposed test fixture. The results of this experiment will be estimates for the operating temperature and cool-down time of the detector, experience with the process of bolting the cold head to the thermosyphon, and a recommendation for the applied bolt pressure. The concept is to build a test bench were heat will be applied at one end and evacuated at the other end, passing through a copper-to-copper interface. The heat applied will flow through a path leading to a bolted copper-to-copper surface. The heat flow will end in a thermal bath (ice water). See Appendix B for calculations of estimated experiment relative error. Measuring the quantities of heat entering and leaving the joint allows the thermal resistance of the interface to be derived. This experiment will be repeated with different seal pressures and bolt configurations (Parylene-coated vs. uncoated). The experiments will be performed in open air and at room temperature. To avoid measurement errors due to heat flow between the test bench and the surrounding air, the heat measurement path will be placed as close as possible to the joint. Operating at room temperature will allow for an easy (and inexpensive) setup and the results will be extrapolated to cryogenic operation conditions. Figure 5 is a conceptual diagram of the test bench. Vertical orientation allows positioning the physical support of the system at the cold end. The material used to build the experimental setup will be commercially available copper. The results from this experiment will be extrapolated to ultrapure electroformed copper.

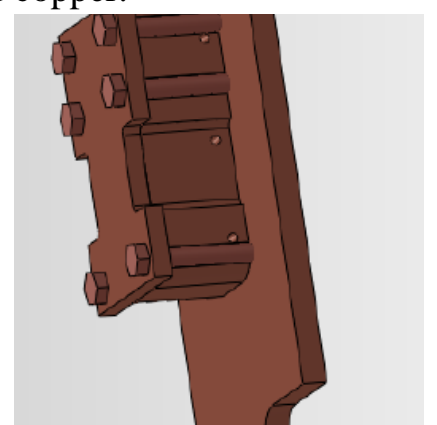

Figure 5. Conceptual Model of the Copper Thermal Joint Test Fixture 


\subsection{Electrical Design}

A displacement current implies a changing electric field, which implies voltages. When a conductive surface is placed across a voltage source there are usually no matching source and terminating impedances. As a result there will be many wave reflections that make the round trip over the length of the wire [Morrison 2007]. This effect could deteriorate the performance of the experiment. The amount of power induced in the conductive surface is proportional to the amount of current moving in and around the experiment. The major source of currents present in a large-mass low-background experiment is complex data acquisition (DAQ) systems positioned relatively close to the detector signal lines. These signal lines are conductive surfaces that pick up generated electric fields. Routing the mirror currents generated by the high speed digital lines of the DAQ is required to eliminate these anomalies in the signal lines.

\subsection{Star Ground Scheme}

Ideally, all voltage drops in the experiment should be referred to a common point, and the electrical path leading to this point should have equal, and minimum, electrical resistance from all points in the electrical layout of the experiment. The return path to ground can get complicated very quickly if the proper electrical breaks are not planned. Separate ground paths for the detectors, the shield, the experiment's Faraday cage and the DAQ systems should be planned. All these ground lines then will be merged at a point such that all systems see the same resistivity in their ground paths. Figure 6 shows a conceptual schematic of a star ground configuration for a low-noise semiconductor-based radiation detection system.

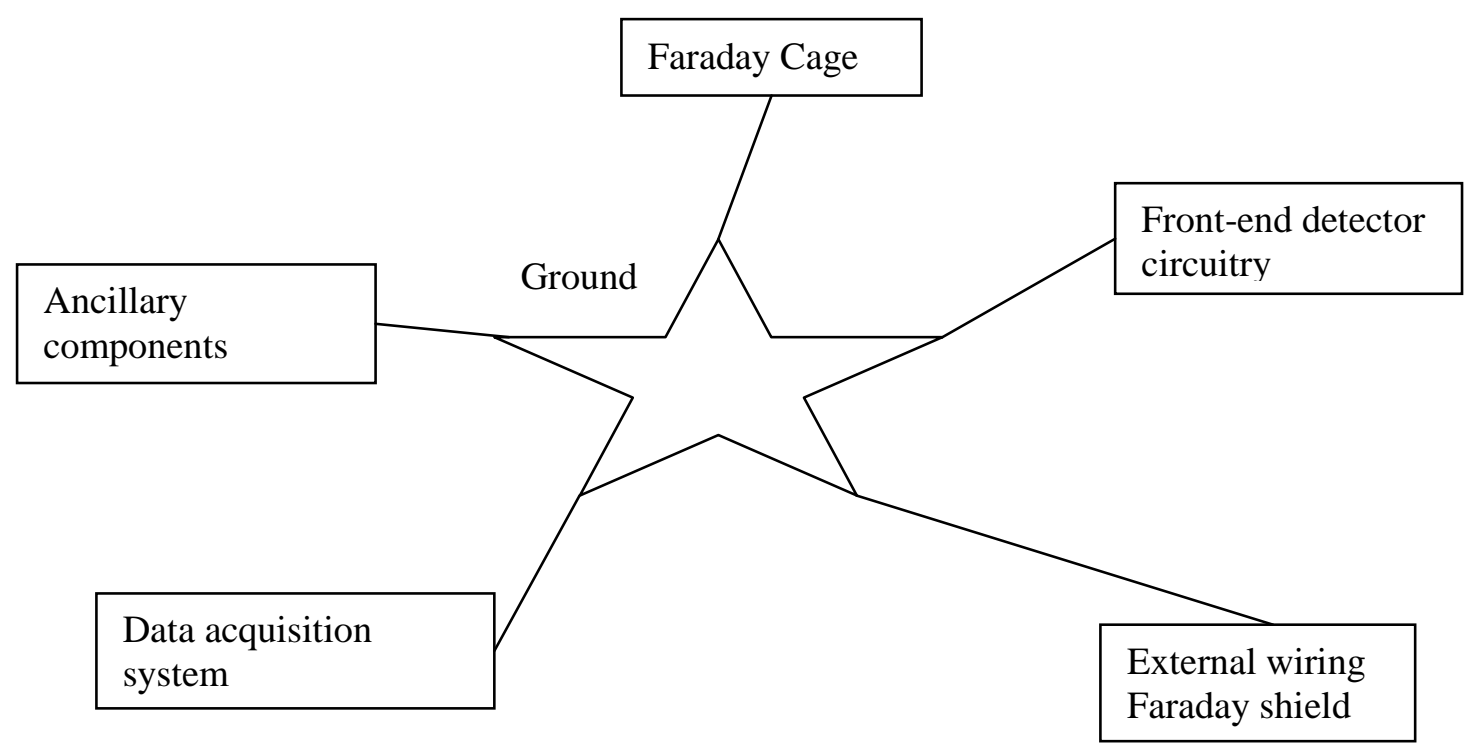

Figure 6. Conceptual Schematics of a Star Ground Configuration

\subsection{Electrical Breaks}

In order to achieve an optimal electrical configuration such as the one presented in Figure 6, electrical breaks must be placed strategically to provide a single path to ground from every conductive 
surface. It might appear as though a simple piece of plastic, ceramic, or mineral would be adequate; however, those materials introduce impurities above required purity levels by outgassing and cannot handle the pressure and/or temperature drops. In the MJD a PYREX transition will insulate the evaporator tube from the rest of the experiment.

\subsection{Faraday Cage}

The Faraday cage of the experiment should be as continuous as possible, and the use of meshed screens to maintain the integrity of the electromagnetic shield should be considered in every port accessing the inner volume of the experiment.

A source of electromagnetic radiation is the electronics components operating inside the detector chamber, such as the field-effect transistor (FET) positioned close to the detector. This fact greatly affects the amount of shielding required for the signal wires and the overall wiring scheme of the experiment. The noise generated inside a Faraday cage populated with current paths is proportional to the number of current paths operating in it simultaneously; there is a proportional relationship between noise and the number of channels. This effect could be attenuated by the use of several layered Faraday cages, which will increase the complexity of the grounding and wiring schemes.

Calculation of the effect of the wiring scheme and number of channels on the noise performance of the system is not trivial. The noise performance is proportional to the received radiated power of each conductor. The waveforms involved in a semiconductor detector experiment are not sinusoids, but resemble step functions. Applying Maxwell's equations to this type of waveforms is complicated. In addition, the frequencies of such signals are unknown, although they can be estimated. This is important because the time that it takes to return most of the radiated energy to the circuit is short compared with the duration of one cycle; as the frequency increases, the time it takes for energy to make a round trip becomes a significant fraction of the operating frequency [Morrison 2007]. A major experimental research effort should be devoted to the study of this effect in order to achieve the sensitivities required for the application of semiconductor detectors to dark-matter searches. In the meantime the following rules of thumb can guide the designer of large-mass low-background experiments toward reducing risk that these effects could play a role in the final performance of the experiment:

1. Distance between signal wires: The power induced by radiation increases with distance from the radiating source. The induction field refers to the field near a loop of current, where the magnetic field dominates. The effect of this induction field is very challenging to shield against.

2. Event rate: The event rate has an effect on the ratio of induced noise on the lines. This is a very intuitive assertion, the more activity on an electrical line, the more interaction with surrounding elements. An experiment with a high event rate is more prone to suffer noise performance degradation due to this effect.

3. Frequency components of the detector signal: The shape of the signal generated in the circuitry affects the difficulty of analyzing the effect of induced field and shielding against it. Sinusoids are the easiest waves to analyze and impulses are the most difficult.

4. Number of channels: This number is proportional to the number of components in the Faraday cage, and also gives an idea of the number of field-generating wires. The number of channels is also proportional to the event rate in the Faraday cage. 
Table 6 presents a relative risk assessment among the four large-mass low-background experiment designs considered by the Majorana collaboration and the 1TGe collaboration. Refer to the corresponding sections at the end of this document for each cryostat for detailed comments (Sections 5-9).

Table 6. Relative Risk of Electromagnetically Induced Noise

\begin{tabular}{lllllc}
\hline Geometry & Distance & Event Rate & Frequency & Channels & Section \\
\hline MJD & Lowest & High & High & Lowest & \\
S4C1 & Low & Highest & High & Low & 5 \\
S4C2 & Highest & Low & Low & Highest & 6 \\
S4C3 & High & Low & High & High & 7 \\
S4C4 & High & Low & Highest & High & 8 \\
S4C5 & High & Low & Highest & High & 9 \\
\hline
\end{tabular}





\subsection{TGe Compact High-Z Shield Cryostat (Shield Geometry \#1) Analysis}

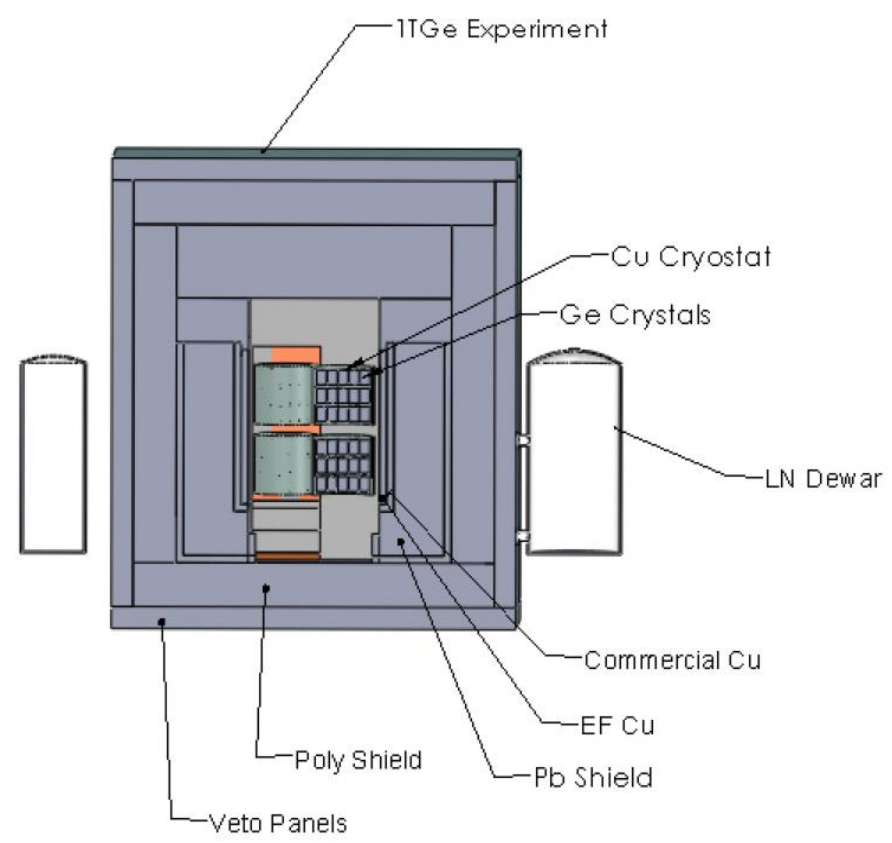

Figure 7. 1TGe Shield Geometry 1 Model [Steele 2011]

\subsection{Description}

This geometry consists of a graded, passive shield with layers of electroformed copper (EFCu) $(10 \mathrm{~cm})$, commercial clean copper $(5 \mathrm{~cm})$, lead $(\mathrm{Pb})(50 \mathrm{~cm})$, and polyethylene $(30 \mathrm{~cm})$, with an outer plastic scintillator anti-cosmic veto shield (10 cm thick) based on a scaled-up MJD. To house $1000 \mathrm{~kg}$ of detectors, two shields are employed, each containing eight $\mathrm{EFCu}, 1-\mathrm{cm}$-thick vacuum cryostats (18" in diameter and 20" long). The line-of-sight exposure of the detectors is optimized by accessing the shield through the side, and avoiding a direct line of sight with the active detector volume. The heat load will be managed by a thermosyphon. The total heat load calculated is $13.1 \mathrm{~W}$ [Reid et al. 2011]. The multiplecryostat configuration helps separate the radiative and conductive heat loads. Separate vacuum systems would minimize vacuum failure risks. The detector mass would be supported by copper and stainless steel welds. An electrical break between the thermosyphon and the cold plate would optimize the electrical configuration. Table 7 contains the identified risks per topic and the proposed actions for the simulation group regarding shield geometry 1 . 
Table 7. Identified Risks and Proposed Actions for Shield Geometry 1

\begin{tabular}{|c|c|}
\hline \multicolumn{2}{|c|}{ Mitigation } \\
\hline \multicolumn{2}{|c|}{ Mechanical } \\
\hline Cold plate bearing $125 \mathrm{~kg}$. & Needs finite-element analysis (FEA) \\
\hline \multicolumn{2}{|r|}{ Thermal } \\
\hline Thermal break in a load-bearing component. & Tortuous stainless steel thermal path \\
\hline \multicolumn{2}{|r|}{ Electrical } \\
\hline $\begin{array}{l}\text { Electrical break in pressurized, ultraclean } \\
\text { cryogenic environment. }\end{array}$ & $\begin{array}{l}\text { The MJD will use PYREX. Investigate the possibility of } \\
\text { having a material capable of electrical isolation closer to } \\
\text { the detector mass. }\end{array}$ \\
\hline
\end{tabular}




\subsection{TGe Direct Immersion in LAr/Water (Shield Geometry \#2) Analysis}

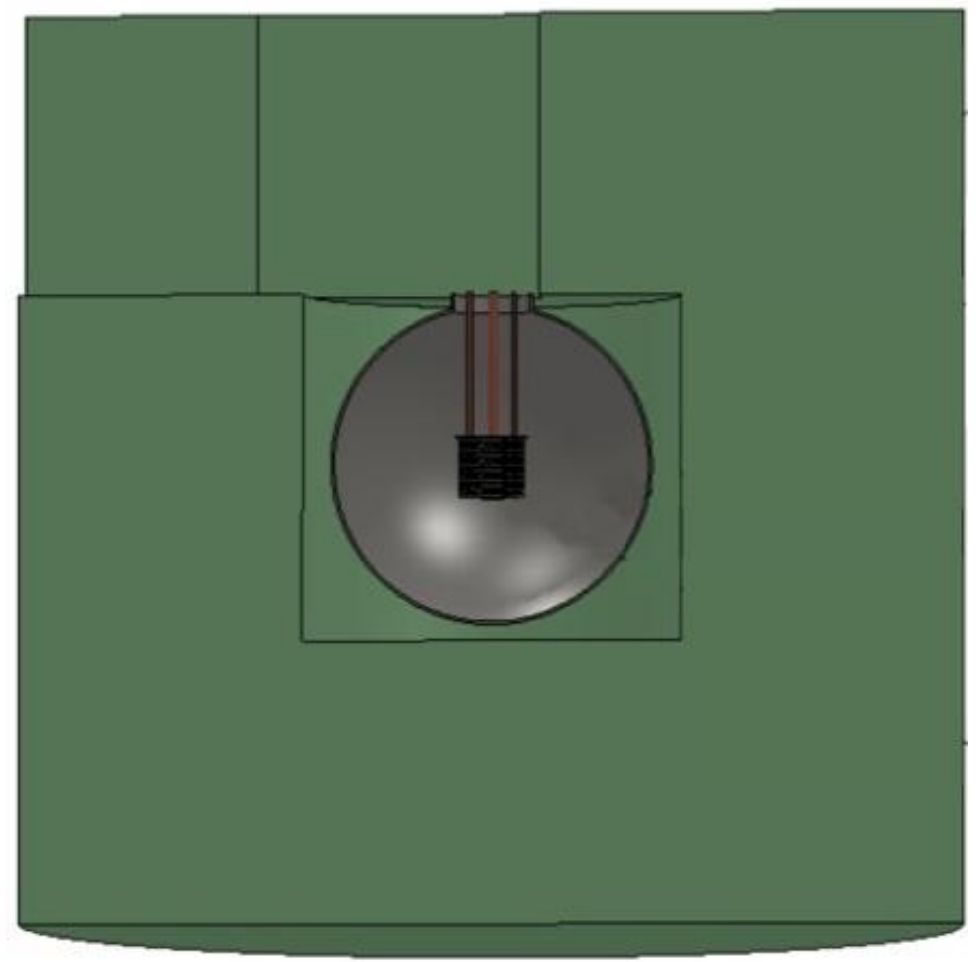

Figure 8. 1TGe Shield Geometry 2 Model [Steele 2011]

\subsection{Description}

In this geometry the HPGe detectors are immersed directly in a 5-m-diameter, 5-cm-thick stainless steel liquid argon (LAr) cryostat with an inner, 10-cm-thick EFCu shield. The cryostat is surrounded by a water-Cherenkov veto tank $15 \mathrm{~m}$ in diameter and $15 \mathrm{~m}$ in height. This geometry will require constant monitoring of the LAr level, since the LAr container would be in direct contact with the external shield. Changes in the level of LAr could mean changes in the resistance of the ground path through the shield and in the capacitance of feed-through lines. This geometry presents a $2.5-\mathrm{m}$ vertical distance to the detector chamber in a direct line-of-sight path to the detectors. A cabling trough for that distance is challenging and the amount of Parylene in the wires could threaten the background budget. Thermal budget for this geometry is simpler than any other proposed geometry. The only heat load component is the heat radiated from the FEE. The support structure would have to bear the weight of the cryogen. Table 8 contains the identified risks per topic and the proposed actions for the simulation group regarding shield geometry 2 . 
Table 8. Identified Risks and Proposed Actions for Shield Geometry 2

\begin{tabular}{|c|c|}
\hline \multicolumn{2}{|c|}{ Mitigation } \\
\hline \multicolumn{2}{|c|}{ Mechanical } \\
\hline Cryostats under pressure $>15$ psi. & $\begin{array}{l}\text { Seals need to be rated for three times the operating } \\
\text { pressure. }\end{array}$ \\
\hline Copper holds the cryostat. & $\begin{array}{l}\text { Electroforming time of a load-bearing part. Limit of weld } \\
\text { strength. }\end{array}$ \\
\hline $\begin{array}{l}\text { Vacuum failure will mean liquid inside the } \\
\text { cryostat. }\end{array}$ & $\begin{array}{l}\text { Sizing of relief valves must account for evacuation of up } \\
\text { to } 50 \% \text { of liquid at a potentially very high drop rate. } \\
\text { Simulate direct opening through shield, to size background } \\
\text { generated. }\end{array}$ \\
\hline Cold plate bearing $250 \mathrm{~kg}$. & Needs FEA. \\
\hline \multicolumn{2}{|r|}{ Thermal } \\
\hline Thermal break in a load-bearing component. & Tortuous stainless steel thermal path \\
\hline $\begin{array}{l}\text { Thermal path from liquid to detectors must } \\
\text { support operating temperature and controlled } \\
\text { temperature gradient among detector channels. }\end{array}$ & $\begin{array}{l}\text { Thermally conducting mesh to inner crystals. A gradient in } \\
\text { temperature from inner to outer detectors is expected. The } \\
\text { amount of thermo-conductive mesh allowed by } \\
\text { background budget would affect temperature performance. }\end{array}$ \\
\hline \multicolumn{2}{|r|}{ Electrical } \\
\hline Electrical break in a load-bearing component. & $\begin{array}{l}\text { Evaluate feasibility of Parylene coating. Simulate Parylene } \\
\text { in supports. Simulate background contribution. }\end{array}$ \\
\hline $\begin{array}{l}\text { Cryostat is a Faraday cage and requires a large } \\
\text { port. }\end{array}$ & Conductive mesh on port. \\
\hline $\begin{array}{l}\text { Wires running in direct line of sight of } \\
\text { detectors. }\end{array}$ & $\begin{array}{l}\text { Simulate the amount of Parylene allowed by background } \\
\text { budget. Might need tortuous support structure. }\end{array}$ \\
\hline
\end{tabular}




\subsection{TGe Vacuum Cryostat in LAr/Water (Shield Geometry \#3) Analysis}

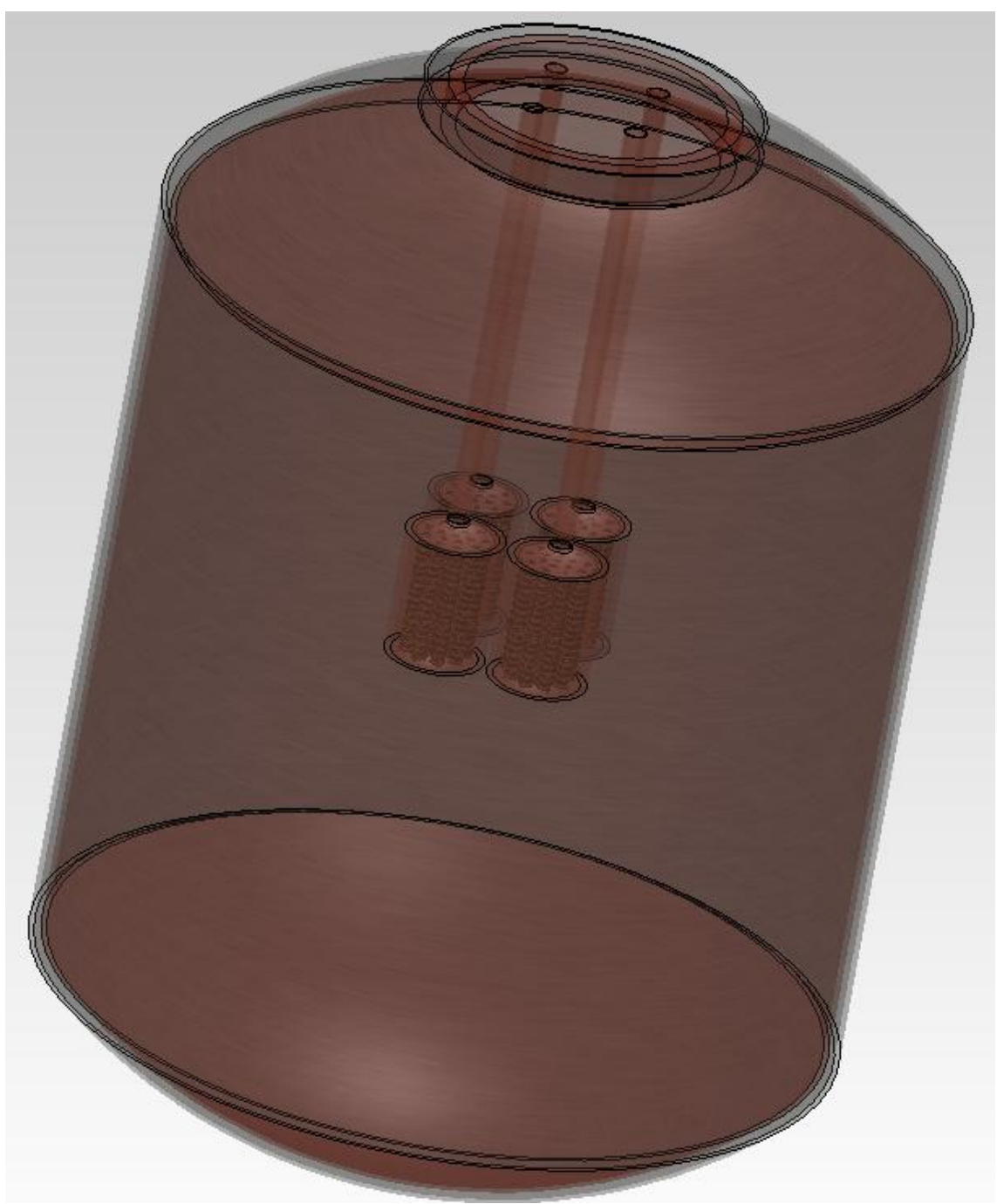

Figure 9. 1TGe Shield Geometry 3 Model [Steele 2011]

\subsection{Description}

This design concept consists of an EFCu vacuum cryostat immersed in a 5-m diameter, 5-cmthick stainless steel LAr cryostat. The cryostat will be built by e-beam welding components that will be assembled into the cryostat. An e-beam welding station will be located on site to avoid above-ground exposure of parts. The cryostats are immersed in liquid argon (density $0.85 \mathrm{~g} / \mathrm{cm}^{3}$ ). The temperature of the fluid will be $87.5 \mathrm{~K}$. Neutron moderation is provided by a layer of water on the walls of the cavern (probably 1- $1.5 \mathrm{~m}$ in thickness), or by a surrounding water tank $15 \mathrm{~m}$ in height and $15 \mathrm{~m}$ in diameter. This geometry presents a 5-m vertical distance to the detector chamber in a direct line-of-sight path to the detectors. A cabling trough that long is challenging and the amount of Parylene in the wires could threaten the background budget. The thermal budget has radiative and conductive components, totaling 
an estimated $7.2 \mathrm{~W}$ per cryostat. The radiative heat component is calculated using the dimensions of the outer shell cylinder $0.43 \mathrm{~m}$ (17') in diameter and $0.86 \mathrm{~m}$ (34") tall. The outer temperature of the cryostat would be LAr temperature and the inner would be liquid nitrogen $(\mathrm{LN})$ temperature. The radiative heat leak is reduced significantly submerging the detector array in liquid argon. A thermosyphon solution is feasible for this conceptual design. The thermal stability of this design could be threatened by the number of detectors operating during the experiment. Since most of the thermal load is from the FEE, a temperature gradient is expected when the operative number of channels changes. In this configuration the cold plate could be held solely by the thermosyphon, eliminating conductive thermal paths to the detector core. Table 9 contains the identified risks per topic and the proposed actions for the simulation group regarding shield geometry 3 .

Table 9. Identified Risks and Proposed Actions for Shield Geometry 3

\begin{tabular}{|c|c|}
\hline Risk & Mitigation \\
\hline \multicolumn{2}{|r|}{ Mechanical } \\
\hline Cryostats under pressure $>15 \mathrm{psi}$ & $\begin{array}{l}\text { Seals need to be rated for three times the operating } \\
\text { pressure }\end{array}$ \\
\hline Copper holds the cryostat. & Electroforming time of a load-bearing part. \\
\hline $\begin{array}{l}\text { Vacuum failure will allow liquid inside } \\
\text { the cryostat. }\end{array}$ & $\begin{array}{l}\text { Sizing of relief valves must account for evacuation } \\
\text { of up to } 50 \% \text { of liquid at a potentially very high drop } \\
\text { rate. }\end{array}$ \\
\hline Cold plate bearing $250 \mathrm{~kg}$. & Needs FEA. \\
\hline \multicolumn{2}{|r|}{ Thermal } \\
\hline $\begin{array}{l}\text { Thermal break in a load-bearing } \\
\text { component. }\end{array}$ & Tortuous stainless steel thermal path \\
\hline Main component of heat load is FEE & Possible radial temperature variation. \\
\hline \multicolumn{2}{|r|}{ Electrical } \\
\hline $\begin{array}{l}\text { Electrical break in a load-bearing } \\
\text { component. }\end{array}$ & Parylene coating feasible? \\
\hline $\begin{array}{l}\text { Cryostat acts as Faraday cage and needs a } \\
\text { big port. }\end{array}$ & Conductive mesh on port. \\
\hline $\begin{array}{l}\text { Wires running in direct line of sight to } \\
\text { detectors }\end{array}$ & $\begin{array}{l}\text { Simulate the amount of Parylene allowed by } \\
\text { background budget. Might need tortuous support } \\
\text { structure. }\end{array}$ \\
\hline
\end{tabular}




\subsection{TGe Vacuum Cryostat in Liquid Scintillator (Shield Geometry \#4) Analysis}

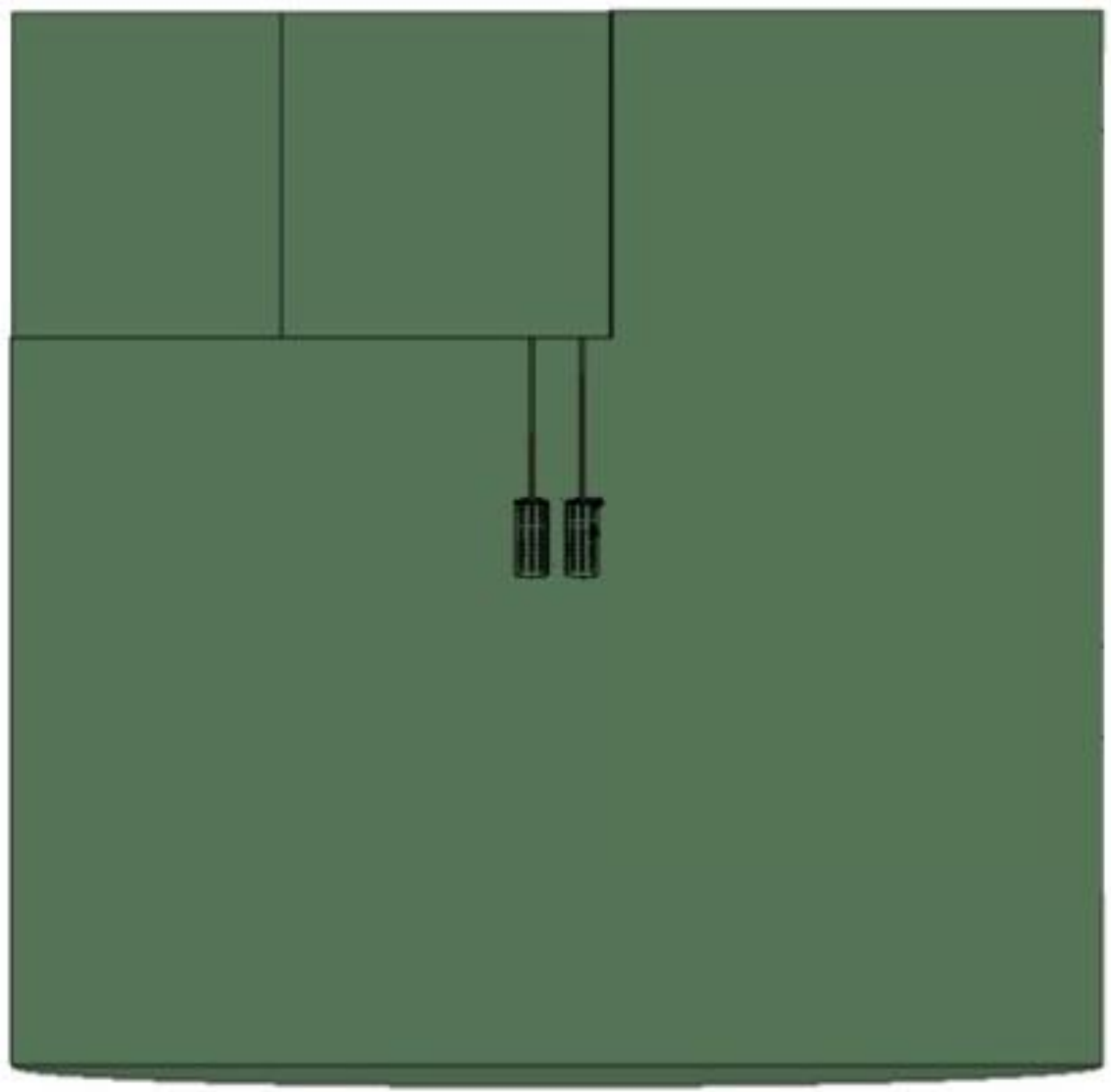

Figure 10. 1TGe Shield Geometry 4 Model [Steele 2011]

\subsection{Description}

This design concept employs four EFCu vacuum cryostats $0.48 \mathrm{~m}$ (19") in diameter and tall enough to hold $250 \mathrm{~kg}$ of HPGe (height estimated to be $0.76 \mathrm{~m}$ (30")). The cryostat will be built by ebeam welding components that will be assembled into the cryostat. An e-beam welding station will be located on site to avoid above-ground exposure of parts. The cryostats will be immersed in a liquid scintillator (LAB), density $0.85 \mathrm{~g} / \mathrm{cm}^{3}$ ) in a stainless steel tank approximately 11 to $15 \mathrm{~m}$ in diameter and $15 \mathrm{~m}$ in height. The fluid will be at room temperature. The cryostats will be held by a vertical copper rod acting as a thermosyphon, eliminating thermally conductive paths to the detector core. This geometry presents a several-meter vertical distance to the detector chamber in a direct line-of-sight path to the detectors. A cabling trough that long is challenging and the amount of Parylene in the wires could threaten the background budget. The thermal budget has radiative and FEE components, totaling an estimated $12.45 \mathrm{~W}$ per cryostat. Table 10 contains the identified risks per topic and the proposed actions for the simulation group regarding shield geometry 4. 
Table 10. Identified Risks and Proposed Actions for Shield Geometry 4

\begin{tabular}{ll}
\hline Risk & Mitigation \\
\hline Cryostats under pressure $>15 p s i$ & Mechanical \\
& $\begin{array}{l}\text { Seals need to be rated for three times the operating } \\
\text { pressure }\end{array}$ \\
Copper holds the cryostat. & $\begin{array}{l}\text { Electroforming time of a load-bearing part. } \\
\text { Vacuum failure will allow liquid inside the }\end{array}$ \\
$\begin{array}{ll}\text { Sizing of relief valves must account for evacuation of up } \\
\text { to 50\% of liquid at a potentially very high drop rate. }\end{array}$ \\
Cold plate bearing 250 kg. & Needs FEA \\
\hline & Thermal \\
\hline Thermal break in a load-bearing component. & Tortuous stainless steel thermal path \\
Thermosyphon room-temperature load & Proper sizing of ballast tank and thermal load of cryostat \\
requires pressure rating of inner space & to minimize initial working fluid pressure. \\
components three times the initial load. & \\
\hline & Electrical \\
\hline Electrical break in a load-bearing component. & Parylene coating feasible? \\
Cross arm outside Faraday cage & Electrical-break materials close to detector \\
\hline
\end{tabular}




\subsection{TGe Vacuum Cryostat in Water (Shield Geometry \#5) Analysis}

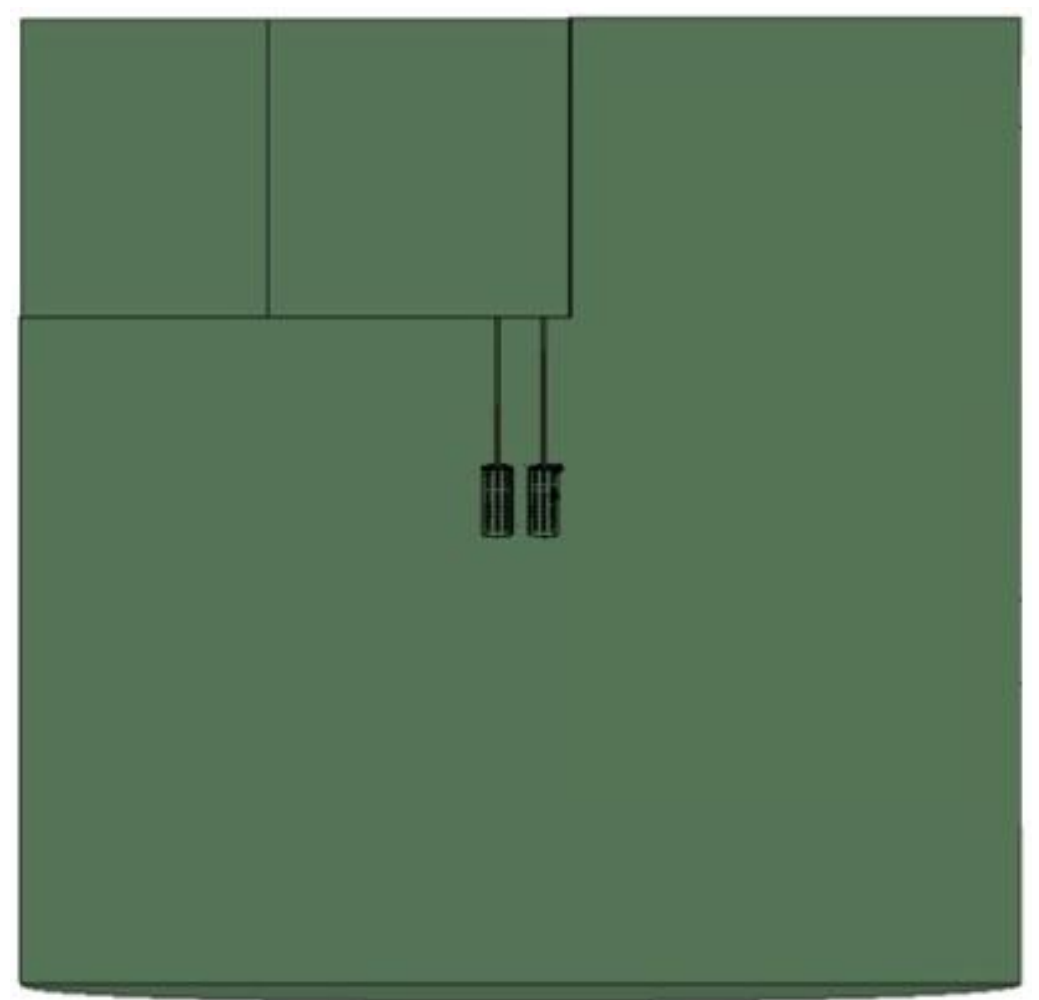

Figure 11. 1TGe Shield Geometry 5 Model [Steele 2011]

\subsection{Description}

This design concept employs four EFCu vacuum cryostats $0.48 \mathrm{~m}$ (19") in diameter and tall enough to hold $250 \mathrm{~kg}$ of HPGe (estimated height $0.76 \mathrm{~m} \mathrm{(30")).} \mathrm{The} \mathrm{cryostat} \mathrm{will} \mathrm{be} \mathrm{built} \mathrm{by} \mathrm{e-beam}$ welding components that will be assembled into the cryostat. An e-beam welding station will be located on site to avoid above-ground exposure of parts. The cryostats will be immersed in water in a stainless steel tank approximately 11 to $15 \mathrm{~m}$ in diameter and $15 \mathrm{~m}$ in height. The fluid will be at room temperature. The cryostats will be held by a vertical copper rod acting as thermosyphon and eliminating thermally conductive paths to the detector core. This geometry presents a several-meter vertical distance to the detector chamber in a direct line-of-sight path to the detectors. A cabling trough that long is challenging and the amount of Parylene in the wires could threaten the background budget. Thermal budget has radiative and FEE components, and is estimated at $12.45 \mathrm{~W}$ per cryostat. Table 11 contains the identified risks per topic and the proposed actions for the simulation group regarding shield geometry 5. 
Table 11. Identified Risks and Proposed Actions for Shield Geometry 5

\begin{tabular}{|c|c|}
\hline Risk & Mitigation \\
\hline \multicolumn{2}{|r|}{ Mechanical } \\
\hline Cryostats under pressure $>15 \mathrm{psi}$. & $\begin{array}{l}\text { Seals need to be rated for three times the operating } \\
\text { pressure. }\end{array}$ \\
\hline Copper holds the cryostat. & Electroforming time of a load-bearing part. \\
\hline $\begin{array}{l}\text { Vacuum failure will allow liquid inside the } \\
\text { cryostat. }\end{array}$ & $\begin{array}{l}\text { Sizing of relief valves must account for evacuation } \\
\text { of up to } 50 \% \text { of liquid at a potentially very high drop } \\
\text { rate. }\end{array}$ \\
\hline Cold plate bearing $250 \mathrm{~kg}$. & Needs FEA \\
\hline \multicolumn{2}{|r|}{ Thermal } \\
\hline $\begin{array}{l}\text { Thermal break in a load-bearing } \\
\text { component. }\end{array}$ & Tortuous stainless steel thermal path \\
\hline $\begin{array}{l}\text { Thermosyphon room-temperature load } \\
\text { requires pressure rating of inner space } \\
\text { components three times the initial load. }\end{array}$ & $\begin{array}{l}\text { Proper sizing of ballast tank and thermal load of } \\
\text { cryostat to minimize initial working fluid pressure. }\end{array}$ \\
\hline \multicolumn{2}{|r|}{ Electrical } \\
\hline $\begin{array}{l}\text { Electrical break in a load-bearing } \\
\text { component. }\end{array}$ & Parylene coating feasible? \\
\hline Cross arm outside Faraday cage & Electrical-break materials close to detector \\
\hline
\end{tabular}




\subsection{References}

1. [Aalseth 2010a]Aalseth, CE, Aguayo, M. Amman, F.T. Avignone III, H.O. Backe, X. Bai, A.S. Barabash, P.S. Barbeau, M. Bergevin, F.E. Bertrand, M. Boswell, V. Brudanin, W. Bugg, T.H. Burritt, M. Busch , G. Capps, Y-D. Chan, J.I. Collar, R.J. Cooper, R. Creswick, J.A. Detwiler, J. Diaz, P.J. Doe, Yu. Efremenko, V. Egorov, H. Ejiri, S.R. Elliott, J. Ely, J. Esterline , H. Farach, J.E. Fast, N. Fields, P. Finnerty, F.M. Fraenkle, V.M. Gehman, G.K. Giovanetti , M. Green, V.E. Guiseppe, K. Gusey, A.L. Hallin, G.C. Harper, R. Hazama, R. Henning , A. Hime, H. Hong, E.W. Hoppe, T.W. Hossbach, S. Howard, M.A. Howe, R.A. Johnson, K.J. Keeter, M. Keillor, C. Keller, J.D. Kephart, M.F. Kidd, A. Knecht, O. Kochetov, S.I. Konovalov, R.T. Kouzes, B.H. LaRoque, L. Leviner, J.C. Loach, P.N. Luke, S. MacMullin, M.G. Marino, R.D. Martin, D. Medlin, D.-M. Mei, H.S. Miley, M.L. Miller, L. Mizouni, A.W. Myers, M. Nomachi, J.L. Orrell, D. Peterson, D.G. Phillips II , A.W.P. Poon, O. Perevozchikov, G. Perumpilly, G. Prior, D.C. Radford, D. Reid, K. Rielage, R.G.H. Robertson, L. Rodriguez, M.C. Ronquest, H. Salazar, A.G. Schubert, T. Shima, M. Shirchenko, V. Sobolev, D. Steele, J. Strain, G. Swift, K. Thomas, V. Timkin, W. Tornow , T.D. Van Wechel, I. Vanyushin, R.L. Varner, K. Vetter, K. Vorren, J.F. Wilkerson, B.A. Wolfe, W. Xiang, E. Yakushev, H. Yaver, A.R. Young, C.-H. Yu, V. Yumatov and C. Zhang (The Majorana Collaboration). 2010a. "The MAJORANA Experiment". In Proceedings of the Neutrino Oscillation Workshop (NOW2010), September 4-11, 2010, Conca Specchiulla, Italy.

2. [Aalseth 2010b] Aalseth, C. E., P.S. Barbeau, N.S. Bowden, B. Cabrera-Palmer, J. Colaresi, J.I. Collar, S. Dazeley, P. de Lurgio, G. Drake, J.E. Fast, N. Fields, C.H. Greenberg, T.W. Hossbach, M.E. Keillor, J.D. Kephart, M.G. Marino, H.S. Miley, M.L. Miller, J.L. Orrell, D.C. Radford, D. Reyna, R.G.H. Robertson, R.L. Talaga, O. Tench, T.D. Van Wechel, J.F. Wilkerson, K.M. Yocum (CoGeNT collaboration) 2010b. "Results from a Search for Light-Mass Dark Matter with a P-type Point Contact Germanium Detector." Physical Review Letters, (in press) Preprint at http://arxiv.org/abs/1002.4703 (2010).

3. [Reid et al. 2011] Reid DJ, JL Orrell, JE Fast, and E Aguayo Navarrete. 2011. Majorana One-Tonne Cryostat Cooling Conceptual Feasibility Study. PNNL-20150, Pacific Northwest National Laboratory, Richland, WA. .

4. [ASME 2010] ASME BPVC-IX. 2010. "Welding and Brazing Qualifications," Section IX in ASME Boiler and Pressure Vessel Code, American Society of Mechanical Engineers, New York..

5. [Howell 2001] Howell, JR 2001. "SECTION C: Factors From Finite Areas to Finite Areas," A Catalog of Radiation Heat Transfer Configuration Factors, $3^{\text {rd }}$ ed. University of Texas, Department of Mechanical Engineering, Austin, TX. Accessed 3/15/2011 at http://www.me.utexas.edu/ howell/sectionc/C-73.html (last updated March 5, 2001).

6. [Steele 2011] Steele, D. 2011. Telephone communication with David Steele, Los Alamos National Laboratory). February 2011.

7. [CDA 2011] Copper Development Association, Inc. 2011. Fundamentals: Types of Copper and Properties http://www.copper.org/applications/architecture/arch_dhb/fundamentals/intro.html

8. [Morrison 2007] Morrison, R. 2007. Grounding and Shielding: Circuits and Interference, $5^{\text {th }}$ ed. Wiley-Interscience, Hoboken, NJ I 


\section{Appendix A}

\section{Vacuum Failure Heat Leak}





\section{Appendix A - Vacuum Failure Heat Leak}

The size of the pressure relief valve is determined by the maximum allowable pressure inside the experiment chamber, a worst-case scenario in which all the cryogen needs to be evacuated, and the rate of vaporization of the cryogen.

The rate of vaporization is the product of the heat entering the system and the specific heat of vaporization of the cryogen. If only a simple worst-case scenario analysis is to be performed, a number of assumptions need to be made. First, the heat entering the system is approximated to be the radiated heat entering the system. Conduction could occur if cryogen accumulates on the outer surfaces of the experiment's vacuum jacket; the amount of heat entering the system via this mechanism is hard to estimate since the contact surface is unknown. The calculations presented are for the radiative heat entering the MJD experiment's inner volume in the event of a vacuum-failure scenario. The geometry has been divided into two components, the cryostat and the cross-arm tube. Table A.1 presents the calculated heat entering the system through the cross-arm walls. Based on this calculation, up to $500 \mathrm{~W}$ could leak into the vacuum chamber if a vacuum failure occurred.

Table A.1. Heat Leak Calculation for the MJD Experiment in Vacuum-Failure Scenario

\begin{tabular}{|c|c|c|c|c|}
\hline \multicolumn{5}{|c|}{ Vacuum failure calculations for the MAJORANA Thermosyphon } \\
\hline $\begin{array}{l}\text { Heat entering cross-arm vacuum } \\
\text { jacket via conduction }\end{array}$ & Units & Parameters & $\begin{array}{l}\text { Computed } \\
\text { values }\end{array}$ & Comments \\
\hline $\mathrm{T}_{\text {air }}$ & $\mathrm{K}$ & 292 & & \\
\hline $\mathrm{T}$, inner thermosyphon chamber & $\mathrm{K}$ & 80 & & \\
\hline \multicolumn{5}{|c|}{ Inner surface vacuum jacket temperature calculation } \\
\hline Vacuum jacket outer diameter (OD) & $\mathrm{m}$ & 0.0889 & & \\
\hline Outer vacuum jacket surface & $\mathrm{m}^{2}$ & & 0.251359 & \\
\hline Conductivity of copper ( $292 \mathrm{~K})$ & $\mathrm{W} / \mathrm{mK}$ & 393 & & \\
\hline Thickness, vacuum jacket & $\mathrm{m}$ & 0.03175 & & \\
\hline $\mathrm{T}$, inner surface & $\mathrm{K}$ & & 291.8364 & $\mathrm{Q}_{\text {conduction }}=\mathrm{Q}_{\text {convection }}$ \\
\hline Length of evaporator tube & $\mathrm{m}$ & 0.9 & & $\begin{array}{l}\text { Data from MJD SolidWorks } \\
\text { model Feb.16 } 2011\end{array}$ \\
\hline \multicolumn{5}{|l|}{ Heat convection through air } \\
\hline OD of evaporator tube & $\mathrm{m}$ & 0.034 & & $\begin{array}{l}\text { Data from MJD SolidWorks } \\
\text { model Feb.16 } 2011\end{array}$ \\
\hline Evaporator tube outer surface area & $\mathrm{m}^{2}$ & & 0.096133 & \\
\hline Convective heat transfer coefficient & $\mathrm{W} / \mathrm{m}^{2}-\mathrm{K}$ & 25 & & $\begin{array}{l}\text { Worst-case scenario. From } \\
\text { engineeringbox.com }\end{array}$ \\
\hline Heat convection into thermosyphon & $\mathrm{W}$ & & 509.1114 & Newton's Law of Cooling \\
\hline
\end{tabular}





\section{Appendix B}

\section{Expected Error in the Proposed Copper-to-Copper Thermal Joint Test}





\section{Appendix B - Vacuum-Failure Heat Leak}

Equation 1 shows the relationship between temperature difference and heat flow across a conductive heat path.

$$
\mathrm{q}=\frac{\mathrm{k} * \Delta \mathrm{T} * \mathrm{~A}}{\mathrm{~L}}
$$

where:

- $\quad \mathrm{q}$ is the heat flow $(\mathrm{W})$

- $\quad \mathrm{k}$ is the thermal conductivity $(\mathrm{W} / \mathrm{m}-\mathrm{K})$

- A is the area of the heat exchange surface $\left(\mathrm{m}^{2}\right)$

- $\quad \mathrm{L}$ is the length of the heat exchange volume $(\mathrm{m})$

- $\Delta \mathrm{T}$ is the temperature difference $(\mathrm{K})$

The heat measurements will be done using a series of thermal sensors in the test bench. The first sensor will be placed at the heat-source end of the test bench. The heat source is a resistor with a regulated voltage source, so the amount of heat can be adjusted. The heat entering the joint will be measured using two temperature sensors along a machined path immediately following the heat source. This component, acting as thermal path, will be made of material that will allow evaluation within a predetermined tolerance of the temperature gradient across the material for the expected heat flow. Six thermal sensors will be aligned along the thermal joint. The heat leaving the thermal joint will be measured using the same machined thermal-path geometry and material from the copper-to-copper joint to the heat sink. Two thermocouples, placed at each end of the thermal path to a cold bath, will measure the outward flow of heat. This measurement will have the same predetermined tolerance as that of the heat entering the joint. The last component of the test bench is a heat sink. This heat sink will be constructed using an ice water bath that will provide great heat capacity.

The thermal sensor proposed for this experiment is a platinum thin-film resistive thermal device (Pt RTD) manufactured by Sensor Scientific, Inc. Platinum RTDs feature a stable output over a long period of time, ease of recalibration, and accurate readings over narrow temperature spans. Disadvantages, when compared to the thermocouples, are: smaller overall temperature range, higher initial cost and less durability. The dimensions are $2.3 \mathrm{~mm}$ in length, $2.1 \mathrm{~mm}$ wide, and a height of 0.9 $\mathrm{mm}$. The manufacturer alerts that if elements are encapsulated in a potting compound one must make sure that the compound will not induce pressure loads, which would result in a strain-gauge effect. The response time for this thermal sensor is reported by the manufacturer to be a maximum of 10 seconds; the elements have a resistance of $1000 \mathrm{ohms}$ at $0{ }^{\circ} \mathrm{C}$. The lead wires used to connect the RTD to a readout system can contribute to their measurement error; a cross-calibration of all the Pt RTDs with the lead wires soldered must be carried out before experimentation. The readout of the Pt RTDs will be done using a multi-channel data acquisition system [Aalseth 2010b]. This apparatus features true 61/2-digit (22bit) resolution, up to 200 differential input channels, and built-in temperature measurement functions. 
Table B.1. Sensitivity of test bench components

\begin{tabular}{llll}
\hline Sensor/actuator & Unit & Range of use & Tolerance \\
\hline Pt RTD P100BMB [Aalseth 2010a] & ${ }^{\circ} \mathrm{C}$ & -70 to +500 & 0.3 (at 0 C) \\
Pressure film [Howell 2001] & $\mathrm{psi}$ & $350-1400$ & Not specified \\
Heat source & $\mathrm{W}$ & $5-30$ & 1 \\
\hline
\end{tabular}

The uncertainty in the heat measurement with respect to the uncertainty in the temperature measurement in a conductive path is given by Equation 2:

$$
u\{q\}=u\left\{\frac{\mathrm{k} * \Delta \mathrm{T} * \mathrm{~A}}{\mathrm{~L}}\right\}=\frac{\mathrm{k} * \Delta \mathrm{T} * \mathrm{~A}}{\mathrm{~L}} * \sqrt{\left(\frac{\mathrm{u}\{\Delta \mathrm{T}\}}{\Delta \mathrm{T}}\right)^{2}+\left(\frac{\mathrm{u}\left\{\frac{\mathrm{k} * \mathrm{~A}}{\mathrm{~L}}\right\}}{\frac{\mathrm{k} A \mathrm{~A}}{\mathrm{~L}}}\right)^{2}}
$$

The error in the measurement would be maximized when the gradient of temperature across the test bench is minimized. This would occur when the lowest amount of heat passes through the test bench. The minimum heat rate applied to the test bench will be $5 \mathrm{~W}$. The blue line in Figure B.1 shows the calculated error contribution due to uncertainty of the thermal sensor.

The expected radiative heat leakage out of the system can be calculated using the surface of the test bench and the emissivity of the materials used in the setup. Equation 1 shows the relationship between the flow of energy radiated from a hot body to a colder body for a heat-exchange surface area A and temperatures $T_{h}$ and $T_{c}$ respectively.

$$
q=\varepsilon \sigma\left(T_{h}^{4}-T_{c}^{4}\right) A_{c}
$$

where:

- $\quad \mathrm{T}_{\mathrm{h}}$ is the hot body absolute temperature $(\mathrm{K})$

- $\quad \mathrm{T}_{\mathrm{c}}$ is the cold body (surroundings) absolute temperature $(\mathrm{K})$

- $\quad A_{c}$ is the area of the object $\left(\mathrm{m}^{2}\right)$

- $\sigma$ is Boltzman's constant $\left(5.67 * 10^{-8} \mathrm{~W} / \mathrm{m}^{2}-\mathrm{K}^{4}\right)$

- $\varepsilon$ is the emissivity of the object.

The maximum heat loss due to radiation will take place when the maximum amount of heat is going through the entire test bench, that is at the $30-\mathrm{W}$ measurement point. The hottest point in the test bench will be adjacent to the heater, at the top of the thermal path. The expected temperature at this point can be estimated by deriving the expected temperature gradient from the Fourier heat law. The red line in Figure B.1 shows the calculated error contribution due to radiative leakage into the test fixture. 


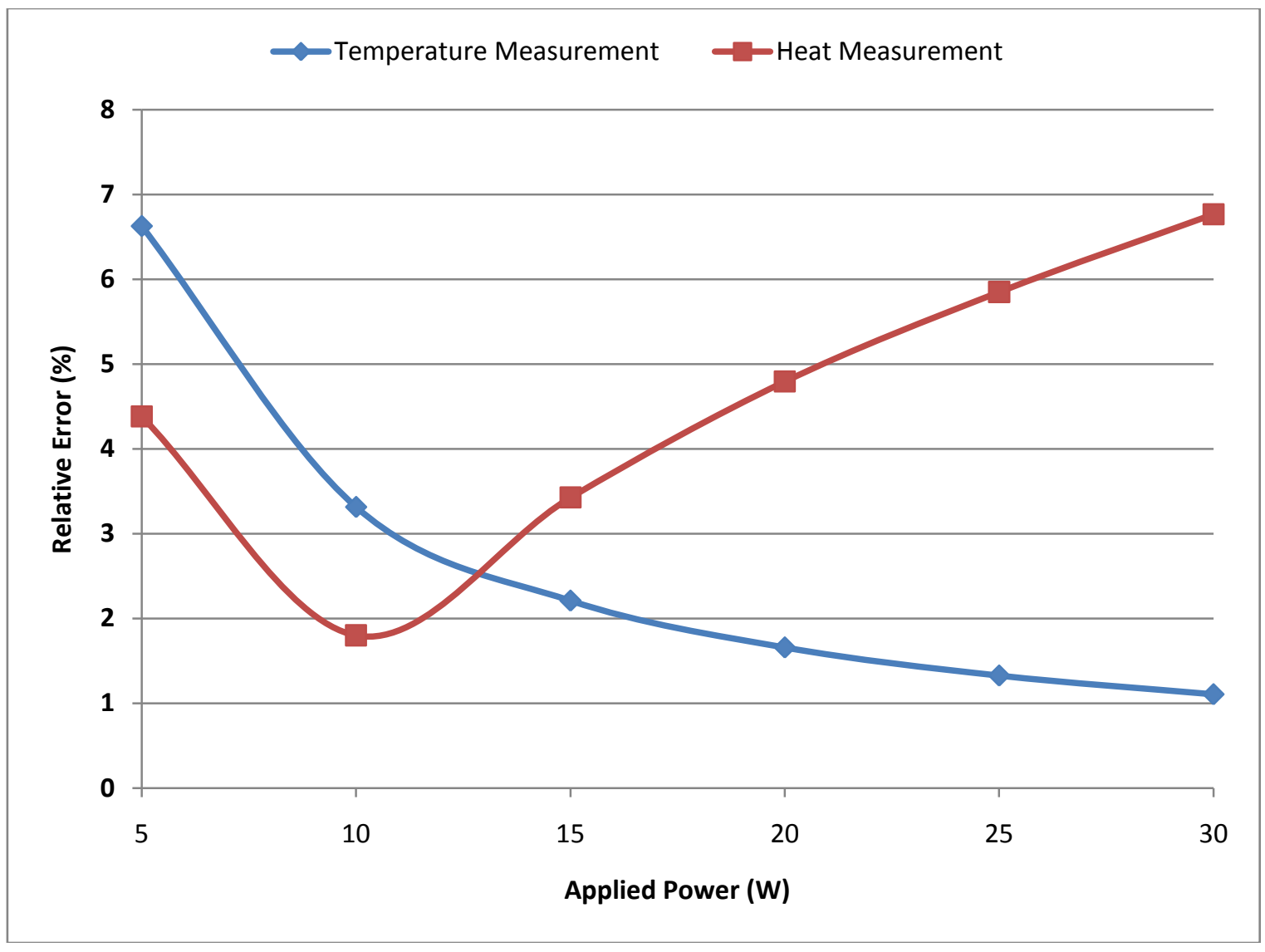

Figure B.1. Calculated Experimental Error by Component versus Power Applied to the Test Fixture 



\section{Distribution}

No. of

Copies

5 Local Distribution

Pacific Northwest National Laboratory

Hanford Technical Library PDF

E Aguayo PDF

DJ Reid PDF

JE Fast PDF

JL Orrell PDF

Distr.1 




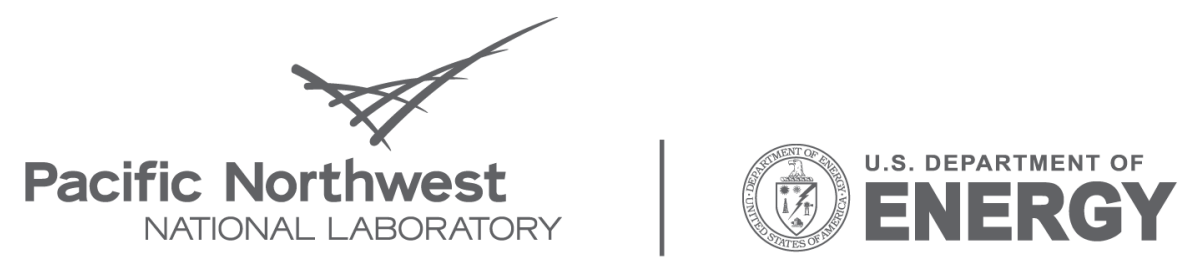

Proudly Operated by Battelle Since 1965

902 Battelle Boulevard

P.O. Box 999

Richland, WA 99352

1-888-375-PNNL (7665)

www.pnl.gov 